\title{
Potential anti-arteriovenous malformations effect of sirolimus on angiogenesis induced by maxillofacial venous hypertension
}

\section{Xiao Li}

Shanghai Jiao Tong University School of Medicine

\section{Zhipeng Gui}

Shanghai Jiao Tong University School of Medicine

Yifeng Han

Shanghai Jiao Tong University School of Medicine

Xitao Yang

Shanghai Jiao Tong University School of Medicine

Zhenfeng Wang

Shanghai Jiao Tong University School of Medicine

Lianzhou Zheng

Shanghai Jiao Tong University School of Medicine

Liming Zhang

Shanghai Jiao Tong University School of Medicine

\section{Deming Wang}

Shanghai Jiao Tong University School of Medicine

\section{Xindong Fan}

Shanghai Jiao Tong University School of Medicine

Lixin Su (D2097275798@qq.com)

Shanghai Jiao Tong University

\section{Research}

Keywords: arteriovenous malformations, vascular anomalies, venous hypertension, sirolimus

Posted Date: September 30th, 2020

DOI: https://doi.org/10.21203/rs.3.rs-80998/v1

License: (1) (1) This work is licensed under a Creative Commons Attribution 4.0 International License.

Read Full License 
Potential anti-arteriovenous malformations effect of sirolimus on angiogenesis induced by maxillofacial venous hypertension

Xiao Li ${ }^{\sharp 1}$, Zhipeng Gui ${ }^{\sharp 2}$, Yifeng Han ${ }^{1}$, Xitao Yang ${ }^{1}$, Zhenfeng Wang ${ }^{1}$, Lianzhou Zheng ${ }^{1}$, Liming Zhang ${ }^{1}$, Deming Wang ${ }^{1, *}$, Xindong Fan ${ }^{1, *}$ and Lixin Su ${ }^{1, *}$

Email: 1315771252@qq.com(X.L.); gzp de@163.com(Z.G.); sarangel@126.com(Y.H.); xitao123456@126.com; seamas97986@126.com(Z.W.); guic217@163.com(L.Z); 302885400@qq.com(L.Z.); wdmdeming@hotmail.com(D.W.); fanxindong@aliyun.com(X.F.); 2097275798@qq.com (L.S.).

1 Department of Interventional Therapy, Shanghai Ninth People's Hospital, Shanghai Jiao Tong University School of Medicine, No. 639 Zhi Zao Ju Rd, Shanghai 200011, Shanghai, People's Republic of China

2 Department of Oral \& Cranio-maxillofacial Surgery, Shanghai Ninth People's Hospital, Shanghai Jiao Tong University School of Medicine, No. 639 Zhi Zao Ju Rd, Shanghai 200011, Shanghai, People's Republic of China

* Correspondence: 2097275798@qq.com; Tel.: +86-021-23271699 (L.S.); fanxindong@aliyun.com; Tel.: +86-021-23271699 (X.F.); wdmdeming@hotmail.com; Tel.: +86-021-23271699 (D.W.).

\#These authors contributed equally to this work and should be considered co-first authors.

\begin{abstract}
Background: This study aimed to explore the possible role and mechanism of venous hypertension $(\mathrm{VH})$ in the occurrence and development of arteriovenous malformations (AVMs) and to study the therapeutic effect of $\mathrm{VH}$ regulation on AVMs to provide insight into AVM pathogenesis and explore new treatments.

Methods: Maxillofacial VH models were established by cervical vascular anastomosis. Osteogenesis and angiogenesis in the model rats were analysed by imaging and histology, and the inhibitory effects of intraperitoneal (ip) sirolimus injection on angiogenesis were detected. The effect of sirolimus on the biological behaviour of human umbilical vein endothelial cells (HUVECs) cultured in vitro and mechanism of sirolimus were detected by cytology.
\end{abstract}


Result: The local microvessel density increased, the vessels showed tortuous dilation, and mRNA and protein levels of angiogenesis-related genes were increased in venous hypertension environment. These phenomena were alleviated or eliminated by ip injection of a sirolimus solution. Sirolimus inhibited proliferation, tubule formation, migration, invasion, angiogenesis-related gene transcription and translation, and phosphorylation of mammalian target of rapamycin (mTOR) and its downstream substrate proteins S6K1 and 4EBP1.

Conclusions: Abnormal angiogenesis caused by $\mathrm{VH}$ is related to abnormal activation of the mTOR pathway, which is important in regulating local angiogenesis; sirolimus inhibited hypertensioninduced excessive angiogenesis in vivo and in vitro through the mTOR signalling pathway. This study provides a basis for further mechanistic study of AVM formation and insight into sirolimus as a possible target drug for AVM management.

Keywords: arteriovenous malformations; vascular anomalies; venous hypertension; sirolimus

\section{Background}

Arteriovenous malformations (AVMs) are congenital high-flow vascular anomalies resulting from direct connections between feeding arteries and outflow veins in the absence of a normal capillary bed [1]. Caused by the lack of buffer and exchange in the capillary bed, AVM lesions are filled with arterial blood and exhibit abnormal haemodynamic changes. Such changes cause a series of clinical symptoms, such as pulsation, a high risk of spontaneous and uncontrolled haemorrhage, and congestive cardiac failure. Treatment modalities for AVMs include endovascular intervention, resection, and laser therapy. One of the most accepted strategies for AVMs is endovascular intervention, which is aimed at occluding the abnormal connections between arteries and veins. However, in advanced AVMs, endovascular intervention does not provide satisfactory results. Advanced AVMs are often associated with a high tendency of progressive aggravation and recurrence [2,3], and their clinical management remains challenging. Recently, medical management for the treatment of venous malformations and lymphatic malformations in a multicentre phase 2 clinical trial was reported [4]. Although evidence to further demonstrate such a strategy is still needed, these results encourage the search for alternative or adjunctive medical therapies to control advanced AVMs.

The mechanisms of AVM formation and progression are largely unknown. The most intuitive way to determine the morphology of this kind of malformation is angiography. Based on previous knowledge about AVMs determined by angiography, the nidus, an abnormal vascular mass that directly shunts blood between the arterial and venous circulation, is a typical pathological feature of 
AVMs [5]. Variable degrees of high flow through the feeding arteries, nidus, and draining veins cause venous hypertension $(\mathrm{VH})$ around the lesion regions, which is among the most critical haemodynamic alterations in AVM [6,7]. Previous studies have demonstrated that the expression levels of vascular endothelial growth factor (VEGF) and hypoxia inducible factor $1 \alpha$ (HIF-1 $\alpha$ ) were significantly upregulated under $\mathrm{VH}$ [8]. Studies have confirmed that continued excessive $\mathrm{VH}$ induced activation of angiogenesis and subsequent vascular remodelling are a potential mechanism of AVMs in the brain [9]. However, as the intracranial environment is largely different from the peripheral environment, whether VH plays a critical role in the formation and progression of peripheral AVMs remains to be explored.

Recent studies have focused on the role of the mammalian target of rapamycin (mTOR) pathway in vascular malformations, and several clinical studies have confirmed the treatment effect of sirolimus. Sirolimus, an immunosuppressive agent used to prevent organ rejection [10], has recently been applied in the management of vascular anomalies, given its anti-angiogenic and antiproliferative properties, with promising results [11-13]. However, the role of sirolimus in AVMinduced VH is not yet clear. The present study was designed to explore mTOR expression in response to VH using an in vivo rat model and examine the effectiveness of sirolimus treatment. In vitro vascular remodelling ability after the knockdown or overexpression of mTOR was also investigated to better explain the potential role of mTOR and the treatment effect of sirolimus in AVM-induced $\mathrm{VH}$.

\section{Methods}

\subsection{Establishment of the In Vivo Maxillofacial VH Model}

Animal experimental protocols were approved by the Institutional Review Board of our institution. Studies involving animals were performed in accordance with the Animal Research: Reporting of In Vivo Experiments (ARRIVE) guidelines. Twenty-nine male Sprague-Dawley rats weighing 350 to $400 \mathrm{~g}$ were used in this study to exclude potential hormonal effects on angiogenesis. All rats were bred and kept in a pathogen-free animal facility.

Rats underwent surgery after the intraperitoneal (ip) injection of $10 \%$ chloral hydrate at a dose of $0.2 \mathrm{~mL} / 100 \mathrm{~g}$ with local anaesthesia. Standard sterile techniques were applied during all procedures. Surgical procedures were performed to induce VH in 22 rats (Fig. 1a and b). First, the proximal segment of the external jugular vein (EJV) and the right anterior facial vein were ligated with 10-0 nylon sutures. Next, the proximal common carotid artery was anastomosed end-to-end to the distal EJV using 11-0 nylon interrupted sutures. The initial portions of the right internal and external carotid arteries were ligated separately. Patency of the bypass and subsequent morphological alteration of the distal EJV were confirmed by invasive venous pressure evaluation at 
1, 2 and 4 weeks after surgery. The other 9 rats, which made up the sham group, underwent a procedure including exposure of the cervical vessels but no occlusion or anastomosis.

The VH rats were randomly assigned to 2 groups according to the intervention protocol with nine rats included in each of the following groups $(n=9)$. The control group received an ip injection of saline (20 mL/kg BW) after surgery. The sirolimus group received a $20 \mathrm{~mL} / \mathrm{kg}$ BW solution ip plus sirolimus (Apexbio, Houston, TX, USA) at a dosage of $1.0 \mathrm{mg} / \mathrm{kg} /$ day after surgery. Rats in the sham group received ip saline injection at the same dose administered to the control group. Intervention continued for 4 weeks, after which all rats were euthanized. The mandibles were harvested from 3 rats in each group, fixed in formalin, embedded in paraffin, and sectioned at $8 \mu \mathrm{m}$ for immunohistochemical or immunofluorescent staining. The bilateral posterior cancellous bone from each of another 3 rats in each group was fractioned for western blot analysis. The posterior cancellous bone was defined as the area around the root tip of the posterior teeth, where the main blood supply of the mandible and a hypoxic microenvironment mainly induced by compromised drainage associated with $\mathrm{VH}$ are located.

\subsection{Haematoxylin and Eosin and Immunofluorescence Staining}

Haematoxylin and eosin (HE) and immunofluorescence staining were performed according to the manufacturer's instructions. After performing the micro PET-CT, the mandible of the rats was cut into hard tissue sections, and the embedding position was located in the mandibular molar area. After completing the hard tissue sectioning, HE staining was carried out, and photos were taken according to the manufacturer's instructions. Briefly, the polished slices were incubated at $60{ }^{\circ} \mathrm{C}$ for $0.5 \mathrm{~h}$ and then treated with different concentrations of methanol as follows: 100\% ethanol for $5 \mathrm{~min}, 95 \%$ ethanol for $5 \mathrm{~min}$, 90\% ethanol for $3 \mathrm{~min}, 90 \%$ ethanol for $3 \mathrm{~min}, 80 \%$ ethanol for $3 \mathrm{~min}$, and $70 \%$ ethanol for $3 \mathrm{~min}$. Then, the slices were stained with haematoxylin for $3 \mathrm{~min}$ and immersed in different concentrations of alcohol as follows: $50 \%, 70 \%$, and $80 \%$. After each treatment for $2 \mathrm{~min}$, the sections were soaked in eosin dye solution for $5 \mathrm{~s}$ and rinsed with ultrapure water for $3 \mathrm{~min}$. The slices were immersed in xylene I and xylene II for 5 mins each, eutral gum was used for sealing, and the slices were observed under a microscope. The immunofluorescence staining was performed according to the manufacturer's instructions. Briefly, after treating the sections with different concentrations of methanol, a 3\% hydrogen peroxide methanol solution was used for soaking at room temperature for $20 \mathrm{~min}$ to inhibit endogenous peroxidase. The antigen was repaired with 0.01 sodium citrate buffer at room temperature, and the slices were sealed with a $5 \%$ BSA solution at $37^{\circ} \mathrm{C}$ for 20 $\min$. The first antibody was incubated at $4{ }^{\circ} \mathrm{C}$ overnight, followed by incubation with 594 regulated affinity donkey anti rabbit IgG $(\mathrm{H}+\mathrm{L})$ (1:200) overnight. DAPI staining was performed for $5 \mathrm{~min}$, followed by three washes with PBS buffer for $5 \mathrm{~min}$ per wash. The immunofluorescence sections were 
observed under a microscope. Five sections were randomly selected from each group. Five visual fields were collected from each section and analysed with ImageJ 1.51j8 image analysis software to determine the $\mathrm{CD} 31$ positive vascular density.

\subsection{Cell Culture}

Human umbilical vein endothelial cells (HUVECs) were used for in vitro studies. HUVECs purchased from Lonza (Walkersville, MD, USA) were cultured in Medium 199 (Invitrogen Corporation, Carlsbad, CA, USA) containing 20\% foetal bovine serum, 5 units $/ \mathrm{ml}$ heparin, $100 \mathrm{ng} / \mathrm{ml}$ streptomycin, 100 units $/ \mathrm{ml}$ penicillin and $3 \mathrm{ng} / \mathrm{ml}$ bFGF under $5 \% \mathrm{CO}_{2} / 95 \%$ air at $37{ }^{\circ} \mathrm{C}$.

\subsection{Overexpression or Knockdown of $m T O R$}

For overexpression experiments, a plasmid vector containing the wild-type mTOR gene was constructed. A TA cloning kit (Invitrogen; Thermo Fisher Scientific; cat No. C45-0046) was used to prepare a PCR product containing the mTOR gene in a plasmid vector according to the manufacturer's protocol. The sequence of the target gene is listed in Supplementary File 3. The clone was ligated into vector PCR 2.1 with the TA cloning kit, and the construct was then transformed into competent $E$. coli cells. The final plasmid, mTOR-pCMV, was verified by sequencing and stored at $20^{\circ} \mathrm{C}$. For mTOR-pCMV transfection, after HUVECs in culture plates reached $80 \%$ confluence, they were collected by trypsinization and counted. The mTOR-pCMV plasmid was transfected into $1 \times 10^{6}$ HUVECs with Nucleofector technology according to the manufacturer's instructions (Amaxa Biosystems, Gaithersburg, MD). The transfected HUVECs were distributed into $10-\mathrm{cm}^{2}$ dishes and continuously cultured at $37^{\circ} \mathrm{C}$ in a humidified incubator with $5 \% \mathrm{CO}_{2}$ for another 24 hours. MTOR overexpression was assessed by measuring the mRNA and protein levels of mTOR using real-time PCR and western blotting, respectively.

For the knockdown of mTOR, SMART pool siRNAs (Dharmacon, Lafayette, CO) were used to silence mTOR with Neucleofector technology following the manufacturer's instructions. Briefly, 100 $\mu \mathrm{L}$ of Neucleofector solution and $100 \mathrm{nM}$ siRNA in an electroporation cuvette were used to suspend 2-3×106 HUVECs. Next, we divided the cells into 12-well plates and incubated the cells in transfection reagent with siRNA in a humidified incubator containing $5 \% \mathrm{CO}_{2}$ at $37^{\circ} \mathrm{C}$ for another 24 hours. After the transfection procedure, $10 \mu \mathrm{M}$ DENSPM was added to the plates.

\subsection{Cell Proliferation Assays}

CCK-8 assays (Dojindo, Japan) were applied to determine cell proliferation according to the manufacturer's protocol. Cells were seeded onto 96-well plates at $2 \times 10^{3}$ cells/well. After attachment, the cells were incubated in culture medium in a humidified incubator containing $5 \% \mathrm{CO}_{2}$ at $37^{\circ} \mathrm{C}$. 
CCK-8 solution was added to each well at the indicated times, and after additional incubation for 2 hours, the OD value at $595 \mathrm{~nm}$ was obtained with a microplate reader (BioTek Synergy HT) to calculate cell viability. In the data analysis, average values from at least three independent experiments were calculated.

\subsection{Cell Migration Assay}

Transwell plates with 6.5-mm diameter polycarbonate filters (Corning Costar Corp., Cambridge, MA, USA) were used to assess the chemotactic motility of cells. Ten micrograms of gelatine was used to coat the lower surface of the filter. Cells were trypsinized and suspended at a concentration of $1 \times 10^{6} \mathrm{cells} / \mathrm{ml}$ in Medium 100. Fresh EGM-2 medium was placed in the lower wells, and $100 \mu \mathrm{L}$ of the cell suspension was loaded into the upper wells. The chamber was incubated at $37^{\circ} \mathrm{C}$ for 4 hours, and the cells were fixed and stained with haematoxylin and eosin (H\&E) with a standard protocol. Nonmigrated cells on the upper surface of the filter were wiped away with a cotton swab. Chemotaxis was quantified by counting the cells on the underneath of the filter with an inverted microscope at low-power magnification (100×).

\subsection{Tube Formation Assay}

A tube formation assay was performed using Matrigel (BD Biosciences) according to the manufacturer's instructions. Briefly, flat-bottom 96-well plates were coated with $50 \mu \mathrm{L}$ of Matrigel. Then, 20,000 HUVECs were added to the wells. Medium containing the appropriate concentration of compounds was added after $30 \mathrm{~min}$, and Matrigel cultures were incubated at $37^{\circ} \mathrm{C}$ to allow cells to form tubular structures. Images were acquired with a 1.4 Mb GiGE colour camera (Hitachi) on a DMI3000B microscope equipped with an automated xyz stage (Leica) using Universal Grab software (version 6.3, DCILabs). Analyses of meshes were performed using ImageJ software. Experiments were performed in quadruplicate.

\subsection{Semiquantitative Reverse-Transcriptase Polymerase Chain Reaction (RT-PCR) and Quantitative Real-} Time PCR ( $q P C R)$

An RNeasy Mini kit (Qiagen, Hilden, Germany) was used to extract total RNA from cells for PCR analysis, and a SuperScript First-strand Synthesis System kit (Invitrogen) was used for reverse transcription according to the manufacturer's instructions. A Platinum Taq Super Mix kit (Invitrogen) was used to perform semiquantitative RT-PCR. The reaction conditions were as follows: predenaturation at $94^{\circ} \mathrm{C}$ for $3 \mathrm{~min}$, followed by 30 cycles of denaturation at $94^{\circ} \mathrm{C}$ for $30 \mathrm{~s}$, annealing at $60^{\circ} \mathrm{C}$ for $30 \mathrm{~s}$, and elongation at $72^{\circ} \mathrm{C}$ for $20 \mathrm{~s}$. 
QPCR was performed with QuantiTect SYBR Green PCR Master Mix (Qiagen) on an ABI Prism 7500 Real-Time PCR System (Applied Biosystems, Carlsbad, CA). The reaction conditions were set as follows: pre-denaturation $94^{\circ} \mathrm{C}$ for $10 \mathrm{~min}$, followed by 40 cycles of denaturation at $94^{\circ} \mathrm{C}$ for $15 \mathrm{~s}$, annealing at $60^{\circ} \mathrm{C}$ for $1 \mathrm{~min}$ and elongation at $72^{\circ} \mathrm{C}$ for $3 \mathrm{~min}$. Each experiment was performed at least three times. The comparative $2^{-\Delta \Delta C t}$ method was applied to calculate relative fold changes in target gene expression. The cDNA concentration for each gene was normalized against that of the GAPDH gene. The primer sequences are listed in Supplementary File 2.

\subsection{Western Blot Analysis}

RIPA buffer (50 mmol/L Tris- $\mathrm{HCl}, \mathrm{pH}$ 8.0, $150 \mathrm{mM}$ sodium chloride, 1\% Triton $\mathrm{X}-100,0.5 \%$ deoxycholic acid, and $0.1 \%$ SDS) was used to prepare protein lysates. A bicinchoninic acid (BCA) assay was used to determine the protein concentration with bovine serum albumin (BSA) as a standard. Sodium dodecyl sulfate-polyacrylamide gel electrophoresis (SDS-PAGE) was used to separate protein lysates (60 $\mu \mathrm{g}$ of protein), and the protein lysates were transferred onto polyvinylidene difluoride membranes. The membranes were blocked in 5\% BSA in Tris-buffered saline/0.05\% Tween 20 (TBS-T) for $30 \mathrm{~min}$ and incubated with the indicated primary antibodies overnight. Then, the membranes were washed and incubated with horseradish peroxidaseconjugated secondary antibodies. An enhanced chemiluminescence solution was used to visualize the immunoreactive bands.

\subsection{Statistical Analysis}

GraphPad Prism software (GraphPad Prism Software, Inc., La Jolla, California) was used for statistical analyses. Means \pm standard deviations (SDs) were applied for the presentation of all data. Analysis by independent sample $t$-test was used to indicate the statistical significance of differences between 2 groups. For multiple comparisons, we used one-way analysis of variance followed by post hoc Student-Newman-Keuls test. Differences were considered statistically significant with a $P$ value calculated as $<0.05$.

\section{Results}

\subsection{Establishment of the Animal Model}

Four rats died during VH induction secondary to surgical failure, giving a mortality of $18.2 \%$ (4/22). Eighteen VH rats were successfully established, and the other 9 rats received a sham operation as the control group. To confirm establishment of the $\mathrm{VH}$ model, we examined the venous pressure of the jugular vein, and our results indicated a higher venous pressure in the $\mathrm{VH}$ group than the 
control group (Fig. 1c). Positron emission tomography/computed tomography (PET-CT) revealed similar mandible bone structures among the three groups (Supplementary File 1).

\subsection{Sirolimus Suppressed Mandibular Angiogenesis Induced by VH In Vivo}

To verify angiogenesis in VH rats and the effect of sirolimus, we analysed the relative area of microvessels in the cancellous bone in the molar region of the mandible. Immunofluorescence staining of rats in the $\mathrm{VH}+$ saline group showed a $\mathrm{DAPI}{ }^{+} / \mathrm{CD} 1^{+}$area in the mandibular cancellous bone, revealing that the relative microvessel area was significantly larger than that in the sham group

(Fig. 2a and b). Further western blot analysis was performed to investigate changes in angiogenic factors (HIF-1 $\alpha$, HIF-2 $\alpha$, TGF- $\beta$, VEGF) in VH rats before and after sirolimus treatment. Both the protein and mRNA levels of the angiogenic factors were elevated in $\mathrm{VH}$ rats compared with control rats (Fig. 2c-k). Interestingly, our results indicated that the relative microvessel area and protein and mRNA levels of the angiogenic factors were suppressed after sirolimus treatment $(\mathrm{VH}+$ sirolimus group) (Fig. 2a-k).

\subsection{Concentration-Dependent Effect of Sirolimus on HUVEC Proliferation, Tube Formation and Migration} In Vitro

CCK-8, tube formation and migration assays were performed to evaluate the effect of sirolimus on the proliferation and formation of endothelial cell networks by HUVECs. Results of the CCK-8 assay showed no significant difference in cell proliferation among the treatment groups $(1 \mathrm{ng} / \mathrm{ml}$ to $1000 \mathrm{ng} / \mathrm{ml}$ ) at 24 hours after incubation with sirolimus ( $\mathrm{P}>0.05)$; however, after 48 hours of incubation with sirolimus, the cell proliferation of the abovementioned treatment groups was lower than that of the control group $(\mathrm{P}<0.05)$ (Fig. 3a).

The ability of the HUVECs to form blood vessels after the treatment with different concentrations of sirolimus was detected by tube formation experiments. The results showed that after growth on vascular Matrigel for 12 hours, the control group and the groups treated with sirolimus at different concentrations all formed obvious tubular structures, and concentrationdependent differences in tube formation were observed: the number of tubules in the $10 \mathrm{ng} / \mathrm{ml}$ sirolimus-treated group was similar to that in the control group, while few, uneven tubules formed in the groups treated with $100 \mathrm{ng} / \mathrm{ml}$ and $1000 \mathrm{ng} / \mathrm{ml}$ sirolimus (Fig. 3b). Quantitative analysis of the number of formed tubules showed no significant difference in the number of formed tubules between the $10 \mathrm{ng} / \mathrm{ml}$ sirolimus-treated group and the control group $(\mathrm{P}>0.05)$, while the numbers of formed tubules in the groups treated with $100 \mathrm{ng} / \mathrm{ml}$ and $1000 \mathrm{ng} / \mathrm{ml}$ sirolimus were lower than that in the control group $(\mathrm{P}<0.05)$ (Fig. 3c). 
The migration of HUVECs treated with different concentrations of sirolimus was evaluated by scratch and Transwell assays. The results of the scratch assay showed that under serum-free culture conditions, 24 hours after the bottom of the cell culture plate was scratched, the cells in the control group and each treatment group showed substantial lateral migration. The horizontal migration of cells in the $10 \mathrm{ng} / \mathrm{ml}$ sirolimus-treated group was similar to that of cells in the control group, while that in the groups treated with $100 \mathrm{ng} / \mathrm{ml}$ and $1000 \mathrm{ng} / \mathrm{ml}$ sirolimus was decreased (Fig. 3d). Quantitative analysis of the relative cell migration area in each group showed no significant difference in relative cell migration area between the $10 \mathrm{ng} / \mathrm{ml}$ sirolimus-treated group and the control group ( $\mathrm{P}>0.05)$, while the relative cell migration areas in the groups treated with $100 \mathrm{ng} / \mathrm{ml}$ and $1000 \mathrm{ng} / \mathrm{ml}$ sirolimus were lower than that in the control group $(\mathrm{P}<0.05)$ (Fig. 3e). Transwell assays showed that after 12, 24 and 48 hours of culture, fewer cells treated with sirolimus at all concentrations examined $(10 \mathrm{ng} / \mathrm{ml}, 100 \mathrm{ng} / \mathrm{ml}$ and $1000 \mathrm{ng} / \mathrm{ml})$ than cells in the control group had migrated to the lower chamber (Fig. 3f). Quantitative analysis of the number of cells in each group that migrated to the lower well of the Transwell chamber showed that compared with the control group, significantly fewer cells in the groups treated with sirolimus at different concentrations (10 $\mathrm{ng} / \mathrm{ml}, 100 \mathrm{ng} / \mathrm{ml}$ and $1000 \mathrm{ng} / \mathrm{ml}$ ) migrated to the lower well ( $\mathrm{P}<0.05)$ (Fig. 3g).

\subsection{Sirolimus Attenuated HUVEC HIF-1 $\alpha$, HIF-2 $\alpha$, VEGF Expression and the mTOR Signalling Pathway}

To further explore the possible causes of the effect of sirolimus on angiogenesis, PCR and western blot assays were used to evaluate the mRNA and protein expression levels, respectively, of factors in HUVECs treated with different concentrations of sirolimus. The PCR results showed that the relative expression levels of VEGF, HIF- $1 \alpha$ and HIF- $2 \alpha$ in the treatment groups were lower than those in the control group when the concentration of sirolimus was $1000 \mathrm{ng} / \mathrm{ml}(\mathrm{P}<0.05)$. When the concentration of sirolimus was $100 \mathrm{ng} / \mathrm{ml}$, the relative expression level of only HIF-2 $\alpha$ was lower than that of the control group after 1 day of treatment, and this difference was statistically significant $(\mathrm{P}<$ 0.05); the expression levels of VEGF and HIF- $1 \alpha$ were not significantly different $(P>0.05)$ than those in the control group after 1 day of treatment. On the 4th and 7th days of drug treatment, the expression of VEGF, HIF-1 $\alpha$ and HIF-2 $\alpha$ in each treatment group was significantly lower than that in the control group $(\mathrm{P}<0.05)$. When the concentration of sirolimus was $10 \mathrm{ng} / \mathrm{ml}$, the expression level of HIF- $2 \alpha$ was slightly lower than that in the control group after only 4 and 7 days of treatment, and this difference was statistically significant $(\mathrm{P}<0.05)$, but expression of these angiogenic genes did not significantly differ at the other detection times $(\mathrm{P}>0.05)$ (Fig. 4a-c).

According to the above experimental results, we selected to use sirolimus at a concentration of $100 \mathrm{ng} / \mathrm{ml}$ for subsequent experiments. Western blot analysis showed that the protein expression levels of HIF- $1 \alpha$, HIF-2 $\alpha$ and VEGF in endothelial cells treated with $100 \mathrm{ng} / \mathrm{ml}$ sirolimus were 
significantly lower than those in the control group and that this difference was statistically significant after one day of sirolimus treatment $(\mathrm{P}<0.05)$. Moreover, the corresponding proteins were significantly downregulated in a time-dependent manner (Fig. $4 \mathrm{~d}$ and e). The western blot analysis of the mTOR pathway-related proteins indicated that these proteins were inhibited in the HUVECs treated with $100 \mathrm{ng} / \mathrm{ml}$ sirolimus. Compared with that in the untreated control group (at 0 hour), the relative expression of phosphorylated mTOR (p-mTOR) was lower after 12 and 24 hours of culture with $100 \mathrm{ng} / \mathrm{ml}$, and this difference was statistically significant $(\mathrm{P}<0.05)$. The expression of phosphorylated ribosomal protein $\mathrm{S} 6$ kinase beta-1 (p-s6k1) and phosphorylated eukaryotic translation initiation factor $4 \mathrm{E}$ binding protein 1 ( $\mathrm{p}-4 \mathrm{ebp} 1)$ was also significantly decreased $(\mathrm{P}<0.05)$ (Fig. 4f-i).

\subsection{The Role of the mTOR Signalling Pathway in the Proliferation, Tube Formation and Migration of} HUVECS

To investigate the role of the mTOR signalling pathway in the biological behaviour of endothelial cells, mTOR overexpression and knockdown cell lines were constructed, and PCR was used to verify the efficacy with which the overexpression plasmid and silencing vector had been constructed. After 48 hours of vector transfection, the mTOR mRNA level was lower in the mTORsilenced group of cells than in the control group, and this difference was statistically significant $(\mathrm{P}<$ 0.05). The mRNA level of mTOR was higher in the mTOR-overexpression group than in the control group, and this difference was statistically significant $(\mathrm{P}<0.05)$ (Fig. 5a). The above results confirmed the successful construction of vectors to regulate the expression level of mTOR.

The proliferation of the HUVECs was detected by a CCK-8 assay after 1, 4 and 7 days of mTOR overexpression. Statistical analysis of the results showed no difference in cell proliferation between the two groups on the first day of culture, but this difference between the two groups was statistically significant $(\mathrm{P}<0.05)$ after 4 and 7 days of culture $(\mathrm{P}<0.05)($ Fig. $5 b)$. The effect of mTOR regulation on the ability of the HUVECs to form blood vessels was examined by tube formation experiments. After growing on vascular Matrigel for 24 hours, the cells in the control group and groups in which mTOR expression was differentially regulated all formed obvious tubular structures. Compared with the control group, the mTOR-silenced group exhibited decreased vascular endothelial tubular formation, and the number of tubular structures was significantly lower than that in the control group $(\mathrm{P}>0.05)$, while the number of tubular structures in the mTOR-overexpression group was significantly greater $(\mathrm{P}<0.05)$ (Fig. $5 \mathrm{c}$ and d). Results of the Transwell assay showed that in serumfree culture, with prolonged culture time, the number of cells in each group that migrated from the upper well to the lower well of the Transwell chamber increased gradually. After 24 and 48 hours of culture, compared with the control group, significantly fewer cells in the mTOR-silenced group 
migrated to the lower well of the Transwell chamber $(\mathrm{P}<0.05)$, while significantly more cells in the mTOR-overexpression group migrated to the lower well of the Transwell chamber $(\mathrm{P}<0.05)$ (Fig. 5e and $f)$.

\subsection{The Effect of mTOR Overexpression or Knockdown on the Expression of Angiogenic Factors and} Proteins Downstream of $m T O R$

Western blot assays were used to detect the effect of mTOR regulation on the angiogenesis of HUVECs and the levels of mTOR pathway-related proteins. According to an analysis of angiogenesis-related proteins in cultured endothelial cells after 4 days, the protein expression levels of HIF-1 $\alpha$, HIF-2 $\alpha$ and VEGF in the mTOR-silenced group were lower than those in the control group, and this difference was statistically significant $(\mathrm{P}<0.05)$; in contrast, those in the mTORoverexpression group were higher than that in the control group, and this difference was statistically significant $(\mathrm{P}<0.05)$ (Fig. 6a and b). Further western blot assays of mTOR pathway-related proteins suggested a clear difference in the levels of mTOR pathway-related proteins in cultured endothelial cells in which the expression of mTOR was regulated after 48 hours. Compared with the control group, the mTOR-silenced group exhibited significantly lower protein expression levels of p-mTOR, $\mathrm{p}-\mathrm{s} 6 \mathrm{k} 1$ and $\mathrm{p}-4 \mathrm{ebp} 1(\mathrm{P}<0.05)$, while the protein expression levels of $\mathrm{p}-\mathrm{mTOR}$, p-s6k1 and p-4ebp1 in the mTOR-overexpression group were higher than those in the control group, and this difference was statistically significant $(\mathrm{P}<0.05)$ (Fig. 6c and f).

\section{Discussion}

In AVMs, which are vascular abnormalities with a high flow velocity, $\mathrm{VH}$ caused by abnormal flow between arteries and veins is one of the most important haemodynamic changes in the process of disease. In the present study, we constructed an animal model of maxillofacial VH to simulate the rushing of arterial blood into venous blood in AVMs. In this model, we found that VH could promote transcription of the VEGF, HIF-1 $\alpha$, HIF-2 $\alpha$ and TGF - $\beta$ genes in local angiogenesis of the jaw, enhance the expression levels of the corresponding proteins, and increase the relative local microvasculature. In model rats with $\mathrm{VH}$, sirolimus could inhibit the $\mathrm{VH}$-induced increase in angiogenesis-related gene transcription, reduce the expression of the corresponding proteins, and restore the local microvascular density and morphology. Our study confirmed that VH has a certain induction effect on local angiogenesis that can be inhibited by sirolimus. We further analysed the regulatory effect of sirolimus on the biological behaviour of HUVECs in vitro. The results of in vitro experiments confirmed that sirolimus could inhibit proliferation, migration, invasion, and the transcription and translation of genes related to angiogenesis. Furthermore, plasmid transfection and RNA silencing confirmed that the mTOR signalling pathway, a biological target of sirolimus, plays 
an important role in proliferation, migration, invasion, and the transcription and translation of angiogenesis-related genes. The present results provide a theoretical basis for the effectiveness of sirolimus in the treatment of vascular malformations and demonstrate the importance of the mTOR signalling pathway in angiogenesis. Our study lays a foundation for further in-depth exploration of the causes of the development of vascular malformations and provides a direction for the identification of more reliable, effective and safe targeted drugs.

In AVM lesions, arteriovenous fistulas are formed due to abnormal connections between arteries and veins, which leads to the direct influx of arterial blood into the venous system. Under the impact of arterial blood, the local vascular morphology was tortuous and dilated, and the walls of veins were dilated and thickened [14]. In some cases, a dense, disordered, and dilated vascular "nest" (nidus) formed in the venous system. This "nest" of blood vessels takes blood from the arterial end and directly drains it into the static venous end. Because this "nest"-like structure of blood vessels does not buffer or exchange substances across normal capillaries and the local blood flow and pressure are higher than those in normal tissues, the "nest"-like structure of blood vessels is the "core" of AVM lesions and the main target of treatment [15]. Therefore, abnormal haemodynamics caused by the vessel "nest" is a hot topic in the field of AVMs. As early as 1992, Spetzler et al. [16] proposed that blood vessel pressure in the lesions rather than the size of lesions affects AVM bleeding. Braverman et al. [17] examined the vascular morphology of patients with hereditary haemorrhagic telangiectasia by ultrasound and noted that high pressure at the venous end may eventually lead to abnormal arteriovenous flow. Nornes and Grip [18] detected the drainage venous pressure of brain AVMs and found that the venous pressure decreased after the removal of intracranial AVMs. In recent years, clinical studies have also noted that in the clinical management of AVMs, local embolization can be used to block local $\mathrm{VH}$, which exerts a relatively satisfactory clinical effect [19]. All the above studies suggest that VH is an important haemodynamic feature of AVMs. In this study, an animal model of maxillofacial $\mathrm{VH}$ was established for the first time, and this model exhibited the characteristics of angiogenesis induced by VH. This animal model of maxillofacial VH successfully simulated the impact of arterial blood flow into the venous system in AVM in vivo and explained the possible causes of the clinical characteristics of AVM, and this models serves as a platform in which to further study the pathological and molecular biological mechanisms of AVM in vivo.

One notable result of this part of the study is that the increased angiogenesis induced by VH in the maxillofacial VH model was inhibited after the ip injection of sirolimus. The microvascular density and transcription of the VEGF, HIF- $1 \alpha$, HIF- $2 \alpha$ and TGF- $\beta$ genes were decreased, the expression of the corresponding proteins was decreased, and the local tortuous dilated vascular morphology was controlled in the sirolimus-injected groups compared to the control group. Sirolimus, also known as rapamycin, is a macrolide antibiotic produced by Streptomyces hygroscopicus. 
In previous studies, sirolimus has shown effective anti-angiogenic properties and can effectively reduce the VEGF content, so it is mostly used in the treatment of tumour diseases [20,21]. In recent years, the use of sirolimus as a drug treatment for vascular diseases such as lymphatic malformation and venous malformation was proposed [22], and a considerable number of cases have confirmed the therapeutic effect of sirolimus in different types of vascular malformations [23,24]. However, to date, medications targeting AVMs remain to be explored. The results of this study confirmed that sirolimus can inhibit angiogenesis induced by $\mathrm{VH}$ in vivo and in vitro. These results suggest that sirolimus is an effective target drug for AVMs that can control the disease by blocking angiogenesis induced by $\mathrm{VH}$. Our results provide a theoretical basis and support for the possible clinical application of sirolimus to treat AVMs in the future.

Sirolimus can inhibit the growth of tumour cells by inhibiting the mTOR signalling pathway in the treatment of tumour diseases [25]. The mTOR protein is a serine/threonine kinase that plays an important role in cell growth, proliferation, angiogenesis, cell metabolism, autophagy and apoptosis. After receiving an upstream stimulus, the mTOR complex can activate and regulate cell behaviour. Therefore, sirolimus may be an effective targeted drug in other diseases involving abnormal regulation of the mTOR pathway [26]. In rat models, activation and overexpression of the serine/threonine-specific protein kinase Akt upstream of mTOR was suggested to lead to vascular malformation [27]. The PTEN gene encodes a tumour suppressor that can inhibit Akt activation. PTEN gene mutations have been found in patients with vascular malformations and high and low flow rates, which may lead to the inhibition of Akt and overexpression of the mTOR pathway [28]. VEGF is a downstream effector of the mTOR pathway that is regulated by the mTOR signalling pathway. Previous studies have noted that in tumours and other diseases, mTOR pathway inhibitors can reduce the secretion of VEGF in tumour cells and reduce the sensitivity of HUVECs to VEGF. This effect was verified both in vivo and in vitro in the present study, which is consistent with previous research results in other diseases $[25,29]$. Therefore, the mTOR pathway may be a key pathway in the process of $\mathrm{VH}$-induced angiogenesis, and inhibition of the mTOR signalling pathway by sirolimus may be a key factor in relieving induced angiogenesis and controlling the development of AVMs. In this part of the study, we found that the high degree of angiogenesis induced by $\mathrm{VH}$ could be inhibited by sirolimus. In vivo, sirolimus was confirmed to inhibit the mTOR signalling pathway; the proliferation, migration and invasion of HUVECs; and the transcription and translation of VEGF, HIF-1 $\alpha$ and HIF-2 $\alpha$. The results of this study provide a theoretical basis and support for sirolimus as a possible target drug in the treatment of AVMs.

Our in vivo study was designed to describe the regulatory role of sirolimus and the mTOR signalling pathway in HUVECs to further clarify the cause of angiogenesis in AVMs and provide direction for targeted therapy. S6K1 and 4EBP1 are the most important substrates in the mTOR 
signalling pathway [30]. Among them, $\mathrm{S} 6 \mathrm{~K} 1$ is a member of the serine/threonine ribosome $\mathrm{S} 6$ kinase family. This kinase contains two kinase catalytic domains, which can phosphorylate a variety of residues in the S6 ribosome. The protein kinase activity of S6K1 can promote protein synthesis and cell proliferation [31]. Previous studies have shown the amplification of the DNA region encoding the S6K1 gene and overexpression of this kinase in breast cancer cell lines. Some scholars have proposed altered translation start sites and transcriptional variants, but further research to confirm these findings is still needed [32]. In contrast, 4ebp1 is a member of the eukaryotic translation initiation factor (EIF) 4E-binding protein family. EIF4G and eIF4E initiation the translation of mRNA after binding, while 4ebp1 and eIF4E act as competitive antagonists of eIF4G, thus partially inhibiting the translation of mRNA. The phosphorylation of 4EBP1 can dissociate eIF4E from eIF4G and activate eIF4G; subsequently, eIF4G and eIF4E act as translation initiators and, thus, promote protein synthesis. Therefore, the phosphorylation of $4 \mathrm{EBP} 1$ is a key factor controlling the initiation of translation and the biological behaviour of many cells [33]. The phosphorylation of ebp1 is a response to exogenous stimuli, which may include hormones, growth factors, mitogens, cytokines, G-protein coupled receptors, and nutritional stress. 4EBP1 is phosphorylated through the following steps. First, the threonine sites at amino acid positions 37 and 46 are phosphorylated by the mTOR protein, after which the carboxyl terminus of 4EBP1 is phosphorylated [34,35]. This study confirmed that the phosphorylation levels of S6K1 and 4EBP1 were changed by regulation of the mTOR pathway by sirolimus; these findings also provide potential targets for the management of AVMs.

A possible limitation of this study is that HUVECs, rather than AVM vascular endothelial cells, were used in the in vivo experiments. Local HUVECs in AVM are not thought to exhibit the level of proliferation observed in tumour cells, but the boundary between AVMs and normal cells is unclear. It was proposed that local AVM cells have the tissue structure and biological characteristics of normal endothelial cells [36]; moreover, because of the great risk of AVM resection, it is very difficult to obtain tissue; thus, normal HUVECs have been used for analysis in previous studies of endothelial cells in this field [9]. Therefore, in our study, the effects of sirolimus were clarified through in vitro experiments using HUVECs, and the effectiveness of the sirolimus treatment was examined in an animal model of $\mathrm{VH}$ in vivo. However, we aim to find a more appropriate animal model and method of cell acquisition from AVMs in future research to further simulate and analyse the local pathological state in AVMs.

\section{Conclusions}

Our present study indicates that abnormal angiogenesis caused by $\mathrm{VH}$ is related to abnormal activation of the mTOR pathway, which plays an important role in the regulation of local angiogenesis; the use of sirolimus could inhibit excessive angiogenesis induced by hypertension in 
vivo and in vitro through the mTOR signalling pathway. Our findings provide a basis for further study of the mechanism of AVM formation and insight into the use of sirolimus as a possible target drug for the management of AVMs.

\section{Supplementary Materials:}

Supplementary File 1: Positron emission tomography/computed tomography (PET-CT) of the mandible bone structures among the three groups.

Supplementary File 2: The primer sequences of the polymerase chain reaction (PCR) analysis.

Supplementary File 3: The sequence of the target mTOR gene.

\section{Declarations}

Funding This work was supported by grants from the National Natural Science Foundation of China [grant number 81871458], the State Key Laboratory of Molecular Engineering of Polymers Fudan University [grant number K2017-03] and a project funded by the China Postdoctoral Science Foundation [grant number 2017M611585].

Conflicts of interest The authors declare no conflict of interest.

Ethics approval and Consent to participate This study was approved by the Ethics Committee of Shanghai Ninth People's Hospital, Shanghai Jiao Tong University School of Medicine. Consent to participate is not applicable because no patient was involved in the present study.

Consent for publication Not applicable

Competing interest The authors declare that they have no competing interests.

Acknowledgements Not applicable 
Availability of data and material The datasets used or analysed during the current study are available from the corresponding author on reasonable request.

Authors' Contributions Conceptualization, X.L., X.F., L.S., D.W., ; methodology, X.L and Z.G.; software, Y.H.; validation, X.Y., Z.W. and L.Z.; formal analysis, L.Z.; investigation, X.L.; resources, X.F.; data curation, Z.G.; writing-original draft preparation, X.L. and Z.G.; writing-review and editing, L.S.; visualization, Z.G.; supervision, D.W.; project administration, X.Y.; funding acquisition, L.S. All authors have read and agreed to the published version of the manuscript. 


\section{References}

1. Liu, A.S.; Mulliken, J.B.; Zurakowski, D.; Fishman, S.J.; Greene, A.K. Extracranial arteriovenous malformations: Natural progression and recurrence after treatment. Plast. Reconstr. Surg. 2010, 125, 1185-1194; DOI:10.1097/PRS.0b013e3181d18070.

2. Leblanc, G.G.; Golanov, E.; Awad, I.A.; Young, W.L. Biology of vascular malformations of the brain. Stroke 2009, 40, e694-e702; DOI:10.1161/strokeaha.109.563692.

3. Young, A.E. Arteriovenous malformations. In Vascular Birthmarks: Hemangiomas and Malformations; Mulliken, J.B., Young, A.R., Eds.; Saunders: Philadelphia, 1988; pp. 228-245.

4. Maruani, A.; Boccara, O.; Bessis, D.; Guibaud, L.; Vabres, P.; Mazereeuw-Hautier, J.; Barbarot, S.; Chiaverini, C.; Blaise, S.; Droitcourt, C.; et al. Treatment of voluminous and complicated superficial slow-flow vascular malformations with sirolimus (PERFORMUS): Protocol for a multicenter phase 2 trial with a randomized observational-phase design. Trials 2018, 19, 340; DOI:10.1186/s13063-018-2725-1.

5. Yakes, W.F.; Rossi, P.; Odink, H. How I do it. Arteriovenous malformation management. Cardiovasc. Intervent. Radiol. 1996, 19, 65-71; DOI:10.1007/bf02563895.

6. Hacein-Bey, L.; Young, W.L. Hemodynamic perturbations in cerebral arteriovenous malformations and management implications. Interv. Neuroradiol. 1999, 5 Suppl 1, 177-182; DOI:10.1177/15910199990050s132.

7. Lawton, M.T.; Rutledge, W.C.; Kim, H.; Stapf, C.; Whitehead, K.J.; Li, D.Y.; Krings, T.; terBrugge, K.; Kondziolka, D.; Morgan, M.K.; et al. Brain arteriovenous malformations. Nat. Rev. Dis. Primers 2015, 1, 15008; DOI:10.1038/nrdp.2015.8.

8. Zhu, Y.; Lawton, M.T.; Du, R.; Shwe, Y.; Chen, Y.; Shen, F.; Young, W.L.; Yang, G.Y. Expression of hypoxia-inducible factor-1 and vascular endothelial growth factor in response to venous hypertension. Neurosurgery 2006, 59, 687-696; discussion 687-696; DOI:10.1227/01.neu.0000228962.68204.cf.

9. Zou, X.; Wu, Z.; Huang, J.; Liu, P.; Qin, X.; Chen, L.; Zhu, W.; Zhao, Y.; Li, P.; Song, J.; et al. The role of matrix metalloproteinase- 3 in the doxycycline attenuation of intracranial venous hypertension-induced angiogenesis. Neurosurgery 2018, 83, 1317-1327; DOI:10.1093/neuros/nyx633.

10. Kasap, B. Sirolimus in pediatric renal transplantation. Pediatr. Transplant. 2011, 15, 673-685; DOI:10.1111/j.1399-3046.2011.01575.x.

11. Kobayashi, S.; Kishimoto, T.; Kamata, S.; Otsuka, M.; Miyazaki, M.; Ishikura, H. Rapamycin, a specific inhibitor of the mammalian target of rapamycin, suppresses lymphangiogenesis and lymphatic metastasis. Cancer Sci. 2007, 98, 726-733; DOI:10.1111/j.1349-7006.2007.00439.x. 
12. Yuksekkaya, H.; Ozbek, O.; Keser, M.; Toy, H. Blue rubber bleb nevus syndrome: Successful treatment with sirolimus. Pediatrics 2012, 129, e1080-e1084; DOI:10.1542/peds.2010-3611.

13. Nadal, M.; Giraudeau, B.; Tavernier, E.; Jonville-Bera, A.P.; Lorette, G.; Maruani, A. Efficacy and safety of mammalian target of rapamycin inhibitors in vascular anomalies: A systematic review. Acta Derm. Venereol. 2016, 96, 448-452; DOI:10.2340/00015555-2300.

14. Shakur, S.F.; Hussein, A.E.; Amin-Hanjani, S.; Valyi-Nagy, T.; Charbel, F.T.; Alaraj, A. Cerebral arteriovenous malformation flow is associated with venous intimal hyperplasia. Stroke 2017, 48, 1088-1091; DOI:10.1161/strokeaha.116.015666.

15. Conway, A.M.; Rosen, R.J. Arteriovenous malformations: Syndrome identification and vascular management. Curr. Treat Options Cardiovasc. Med. 2018, 20, 67; DOI:10.1007/s11936-018-0662-7.

16. Spetzler, R.F.; Hargraves, R.W.; McCormick, P.W.; Zabramski, J.M.; Flom, R.A.; Zimmerman, R.S. Relationship of perfusion pressure and size to risk of hemorrhage from arteriovenous malformations. J. Neurosurg. 1992, 76, 918-923; DOI:10.3171/jns.1992.76.6.0918.

17. Braverman, I.M.; Keh, A.; Jacobson, B.S. Ultrastructure and three-dimensional organization of the telangiectases of hereditary hemorrhagic telangiectasia. J. Invest. Dermatol. 1990, 95, 422-427; DOI:10.1111/1523-1747.ep12555569.

18. Nornes, H.; Grip, A. Hemodynamic aspects of cerebral arteriovenous malformations. J. Neurosurg. 1980, 53, 456-464; DOI:10.3171/jns.1980.53.4.0456.

19. Wang, D.; Su, L.; Han, Y.; Fan, X. Ethanol embolotherapy of high-flow auricular arteriovenous malformations with electrolytically detachable coil-assisted dominant outflow vein occlusion. Eur. J. Vasc. Endovasc. Surg. 2014, 48, 576-584; DOI:10.1016/j.ejvs.2014.08.004.

20. Martinet, W.; De Loof, H.; De Meyer, G.R. mTOR inhibition: A promising strategy for stabilization of atherosclerotic plaques. Atherosclerosis 2014, 233, 601-607; DOI:10.1016/j.atherosclerosis.2014.01.040.

21. Gangloff, Y.G.; Mueller, M.; Dann, S.G.; Svoboda, P.; Sticker, M.; Spetz, J.F.; Um, S.H.; Brown, E.J.; Cereghini, S.; Thomas, G.; et al. Disruption of the mouse mTOR gene leads to early postimplantation lethality and prohibits embryonic stem cell development. Mol. Cell. Biol. 2004, 24, 9508-9516; DOI:10.1128/mcb.24.21.9508-9516.2004.

22. Seront, E.; Van Damme, A.; Boon, L.M.; Vikkula, M. Rapamycin and treatment of venous malformations. Curr. Opin. Hematol. 2019, 26, 185-192; DOI:10.1097/moh.0000000000000498.

23. Escudero-Gongora, M.M.; Corral-Magana, O.; Gomez, C.; Martin-Santiago, A. Topical rapamycin: An additional therapeutic option for tufted angioma in adults. Actas Dermosifiliogr. 2018, 109, 192-194; DOI:10.1016/j.ad.2017.04.026.

24. Chelliah, M.P.; Do, H.M.; Zinn, Z.; Patel, V.; Jeng, M.; Khosla, R.K.; Truong, M.T.; Marqueling, A.; Teng, J.M.C. Management of complex arteriovenous malformations using a novel 
combination therapeutic algorithm. JAMA Dermatol. 2018, 154, 1316-1319; DOI:10.1001/jamadermatol.2018.3039.

25. Guba, M.; von Breitenbuch, P.; Steinbauer, M.; Koehl, G.; Flegel, S.; Hornung, M.; Bruns, C.J.; Zuelke, C.; Farkas, S.; Anthuber, M.; et al. Rapamycin inhibits primary and metastatic tumor growth by antiangiogenesis: Involvement of vascular endothelial growth factor. Nat. Med. 2002, 8, 128-135; DOI:10.1038/nm0202-128.

26. Lackner, H.; Karastaneva, A.; Schwinger, W.; Benesch, M.; Sovinz, P.; Seidel, M.; Sperl, D.; Lanz, S.; Haxhija, E.; Reiterer, F.; et al. Sirolimus for the treatment of children with various complicated vascular anomalies. Eur. J. Pediatr. 2015, 174, 1579-1584; DOI:10.1007/s00431-015-2572-y.

27. Perry, B.; Banyard, J.; McLaughlin, E.R.; Watnick, R.; Sohn, A.; Brindley, D.N.; Obata, T.; Cantley, L.C.; Cohen, C.; Arbiser, J.L. AKT1 overexpression in endothelial cells leads to the development of cutaneous vascular malformations in vivo. Arch Dermatol. 2007, 143, 504-506; DOI:10.1001/archderm.143.4.504.

28. Tan, W.H.; Baris, H.N.; Burrows, P.E.; Robson, C.D.; Alomari, A.I.; Mulliken, J.B.; Fishman, S.J.; Irons, M.B. The spectrum of vascular anomalies in patients with PTEN mutations: Implications for diagnosis and management. J. Med. Genet. 2007, 44, 594-602; DOI:10.1136/jmg.2007.048934.

29. Baldo, P.; Cecco, S.; Giacomin, E.; Lazzarini, R.; Ros, B.; Marastoni, S. mTOR pathway and mTOR inhibitors as agents for cancer therapy. Curr. Cancer Drug Targets 2008, 8, 647-665; DOI:10.2174/156800908786733513.

30. Joly, M. M.; Hicks, D.J.; Jones, B.; Sanchez, V.; Estrada, M.V.; Young, C.; Williams, M.; Rexer, B.N.; Sarbassov dos, D.; Muller, W.J.; et al. Rictor/mTORC2 drives progression and therapeutic resistance of HER2-amplified breast cancers. Cancer Res. 2016, 76, 4752-4764; DOI:10.1158/00085472.can-15-3393.

31. Hong, S.; Zhao, B.; Lombard, D.B.; Fingar, D.C.; Inoki, K. Cross-talk between sirtuin and mammalian target of rapamycin complex 1 (mTORC1) signaling in the regulation of S6 kinase 1 (S6K1) phosphorylation. J. Biol. Chem. 2014, 289, 13132-13141; DOI:10.1074/jbc.M113.520734.

32. Davis, N.M.; Sokolosky, M.; Stadelman, K.; Abrams, S.L.; Libra, M.; Candido, S.; Nicoletti, F.; Polesel, J.; Maestro, R.; D'Assoro, A.; et al. Deregulation of the EGFR/PI3K/PTEN/Akt/mTORC1 pathway in breast cancer: Possibilities for therapeutic intervention. Oncotarget 2014, 5, 4603-4650; DOI:10.18632/oncotarget.2209.

33. Frosi, Y.; Usher, R.; Lian, D.T.G.; Lane, D.P.; Brown, C.J. Monitoring flux in signalling pathways through measurements of 4EBP1-mediated eIF4F complex assembly. BMC Biol. 2019, 17, 40; DOI:10.1186/s12915-019-0658-0. 
34. Beretta, L.; Gingras, A.C.; Svitkin, Y.V.; Hall, M.N.; Sonenberg, N. Rapamycin blocks the phosphorylation of 4E-BP1 and inhibits cap-dependent initiation of translation. EMBO J. 1996, $15,658-664$.

35. Herbert, T.P.; Tee, A.R.; Proud, C.G. The extracellular signal-regulated kinase pathway regulates the phosphorylation of 4E-BP1 at multiple sites. J. Biol. Chem. 2002, 277, 11591-11596; DOI:10.1074/jbc.M110367200.

36. Burns, A.J. Mulliken \& Young's Vascular Anomalies: Hemangiomas and Malformations. Second edition. Plast. Reconstr. Surg. 2015, 135, 1505-1506. 


\section{FIGURES and LEGENDS}

a

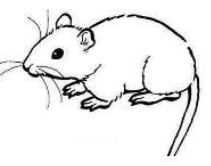

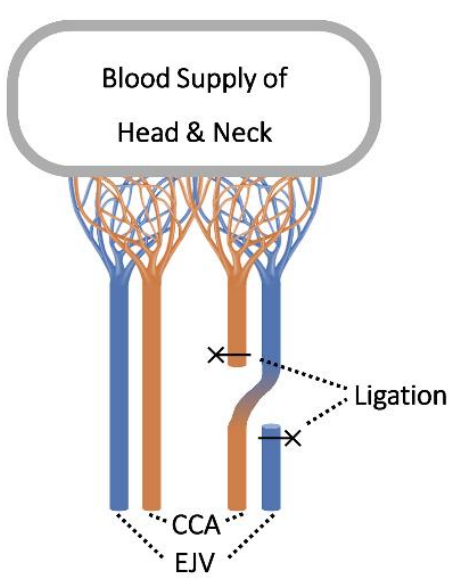

b

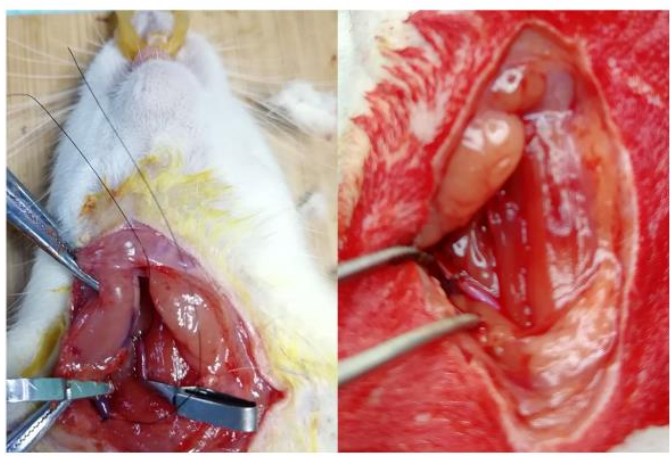

\section{C}

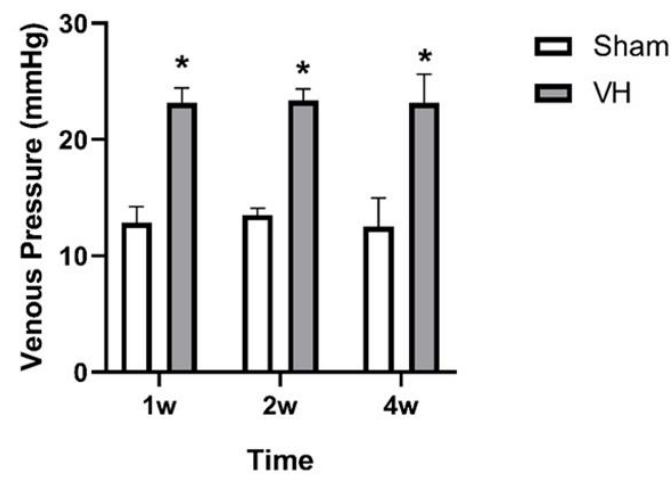

Fig. 1 Establishment of the venous hypertension model. (a) Schematic diagram of the operation procedure. (b) Anastomosis of the common carotid artery and external jugular vein. (c) Venous pressure in the venous hypertension model 1, 2, and 4 weeks after the operation. CCA, common carotid artery. EJV, external jugular vein; Sham: sham group; VH: venous hypertension group. ${ }^{*} p<0.05$ vs the sham group. 

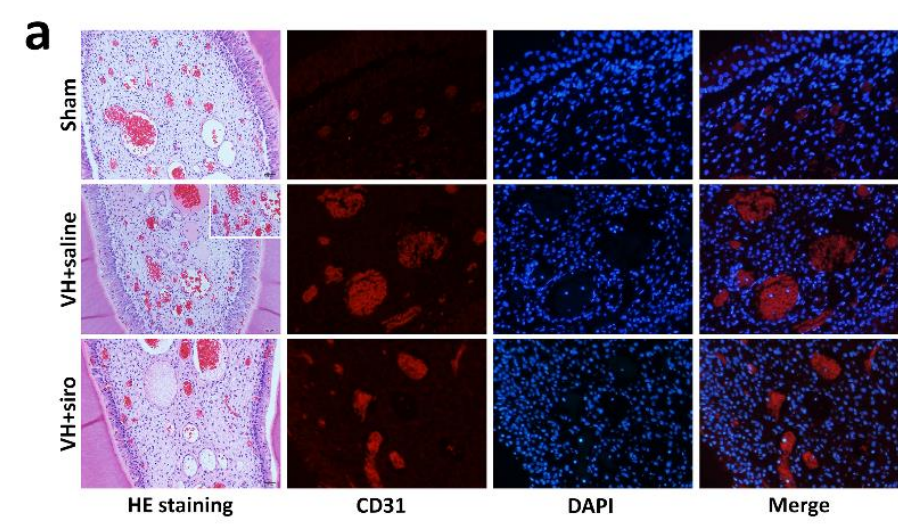

h
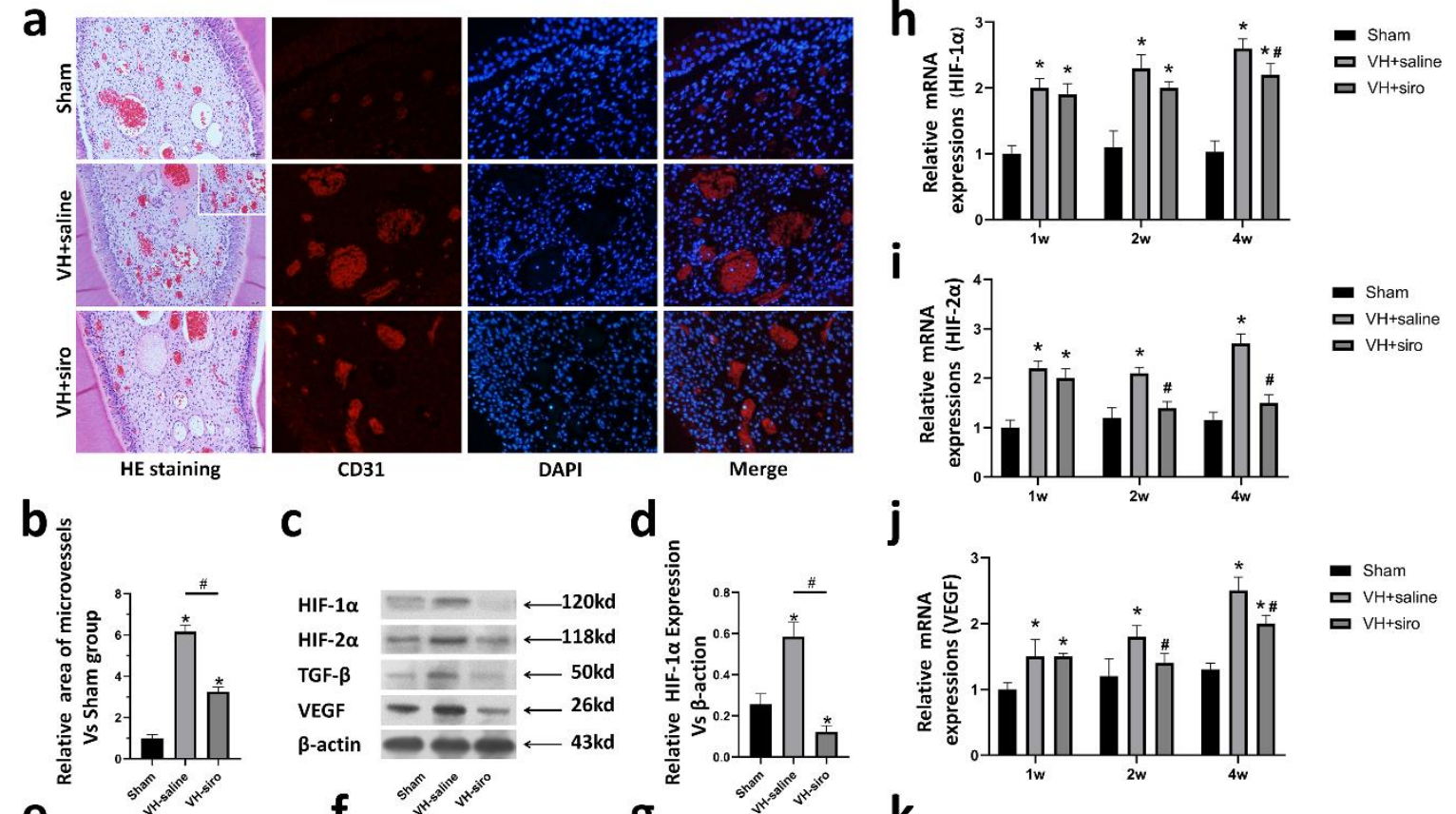

CD31 DAPI

d

c

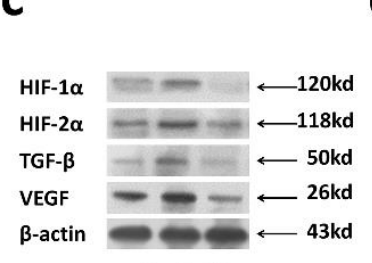

f
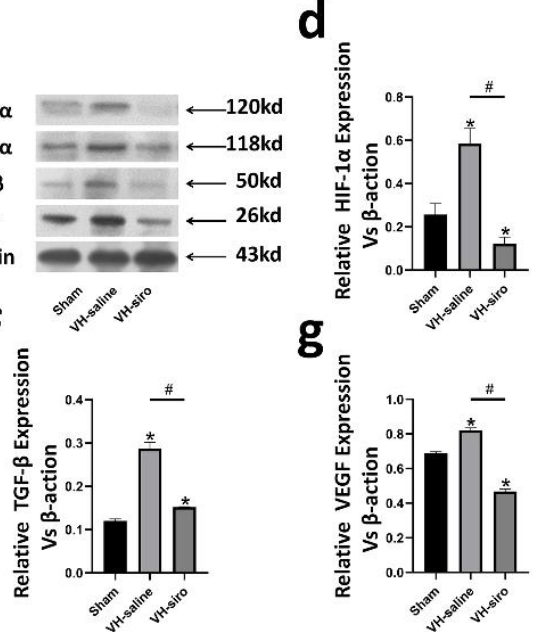

i

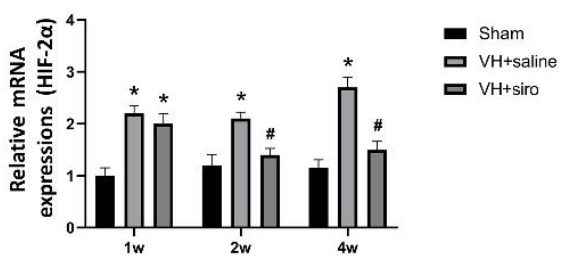

j

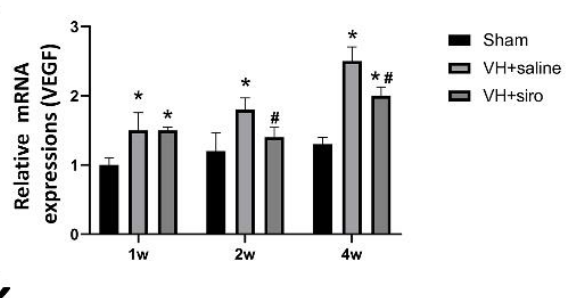

k

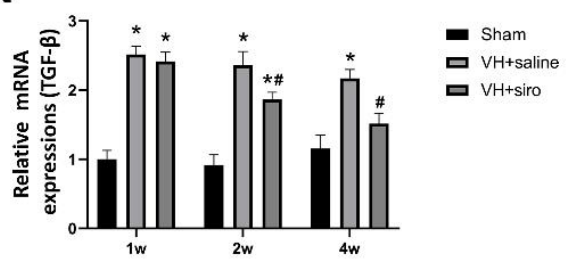

Fig. 2 Sirolimus suppresses mandibular angiogenesis induced by VH in vivo. (a) Haematoxylin and eosin staining and immunofluorescence imaging of mandible in the venous hypertension model 4 weeks after the operation. (b) Relative area of microvessels in mandibular cancellous bone in the venous hypertension model 4 weeks after the operation. (c) Expression levels of angiogenic proteins in mandibular cancellous bone in the venous hypertension model 4 weeks after the operation. (d-g) Relative expression levels of angiogenic proteins in mandibular cancellous bone int the venous hypertension model 4 weeks after the operation. (h-k) Relative mRNA expression levels of angiogenic factors in mandibular cancellous bone in the venous hypertension model 1, 2 and 4 weeks after the operation. Sham: sham group; $\mathrm{VH}+$ saline: venous hypertension group that received a $20 \mathrm{~mL} / \mathrm{kg}$ BW solution ip; $\mathrm{VH}+$ siro: venous hypertension group that received a $20 \mathrm{~mL} / \mathrm{kg} \mathrm{BW}$ solution ip plus sirolimus; HIF-1 $\alpha$ : hypoxia inducible factor-1 alpha; HIF-2 $\alpha$ : hypoxia inducible factor-2 alpha; TGF- $\beta$ : transforming growth factor-beta; VEGF: vascular endothelial growth factor. ${ }^{*} p<0.05$ vs the sham group; \# $p<0.05$ vs the $\mathrm{VH}+$ saline group. 

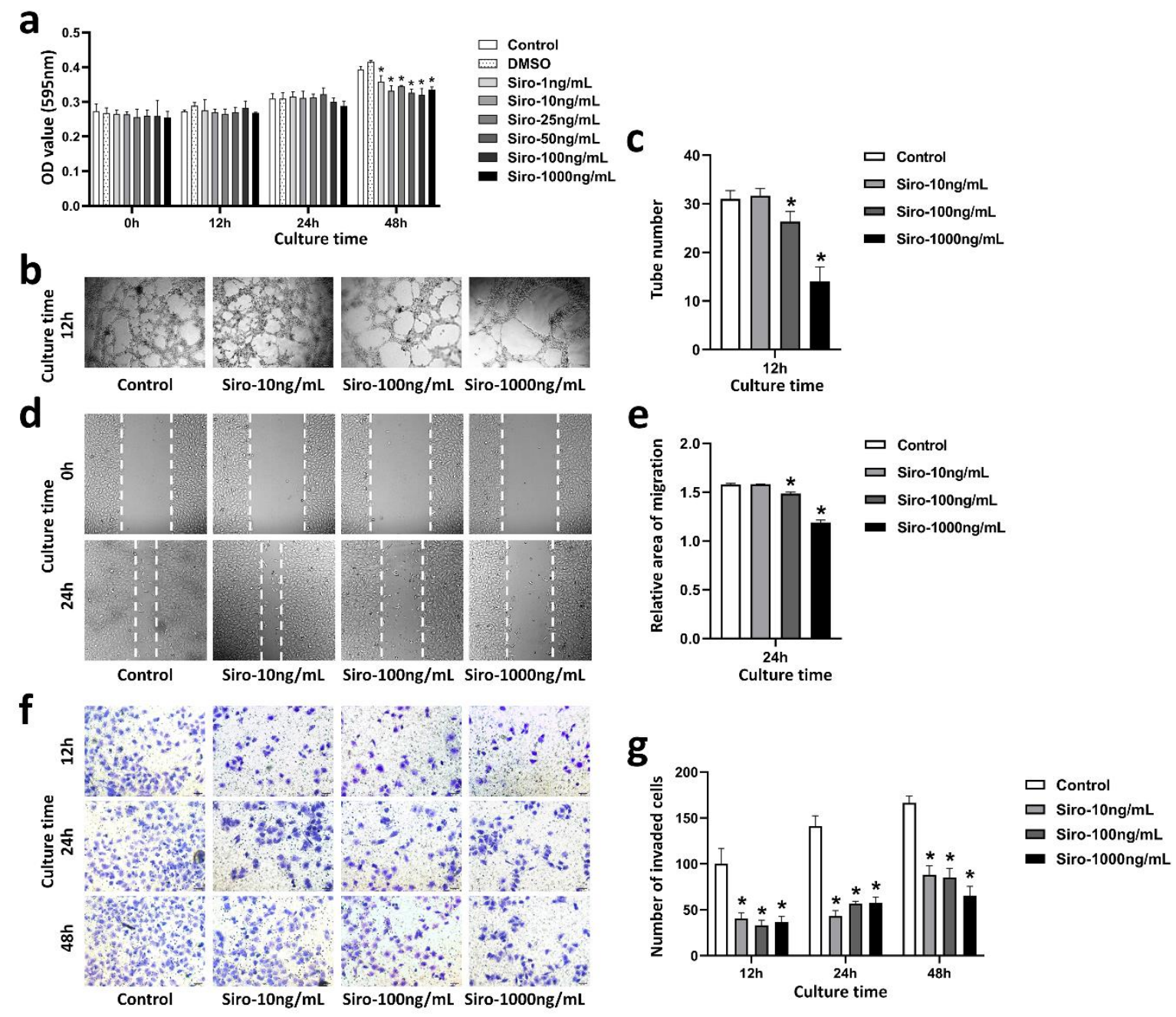

Fig. 3 Sirolimus regulates the biological behaviour of vascular endothelial cells in vitro. (a) CCK-8 proliferation assays of sirolimus-treated vascular endothelial cells. (b) Tube formation assays of vascular endothelial cells treated with sirolimus for $12 \mathrm{~h}$. (c) Quantitative analysis of the tube formation assays of vascular endothelial cells treated with sirolimus for $12 \mathrm{~h}$. (d) Scratch tests of vascular endothelial cells treated with sirolimus for 24 h. (e) Quantitative analysis of the scratch tests of vascular endothelial cells treated with sirolimus for 24 h. (f) Transwell invasion assays of vascular endothelial cells treated with sirolimus for 12, 24 and $48 \mathrm{~h} .(\mathrm{g})$ Quantitative analysis of Transwell invasion assays of vascular endothelial cells treated with sirolimus for 12, 24 and 48 h. Control: control group; DMSO: DMSO-treated group; Siro-n: group treated with different dosages of sirolimus * $p<0.05$ vs the control group. 
a

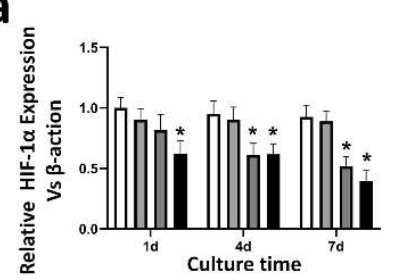

b

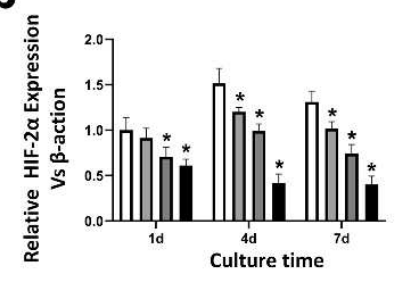

C

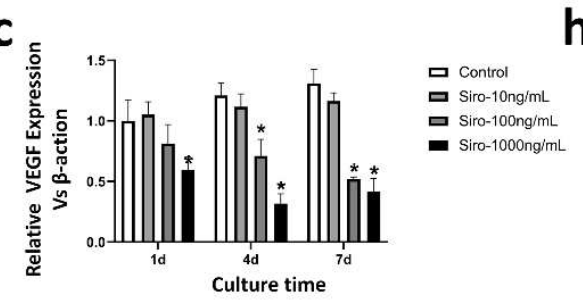

d
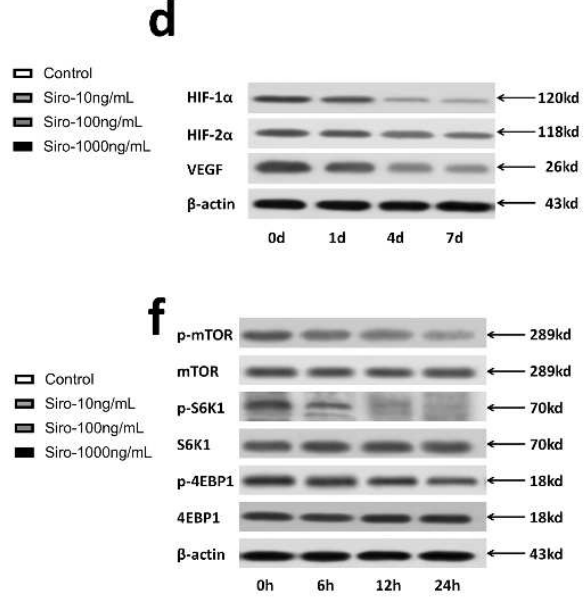

h

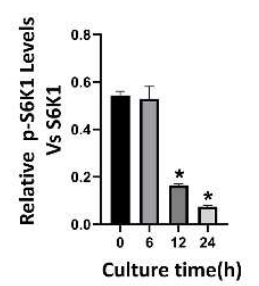

e
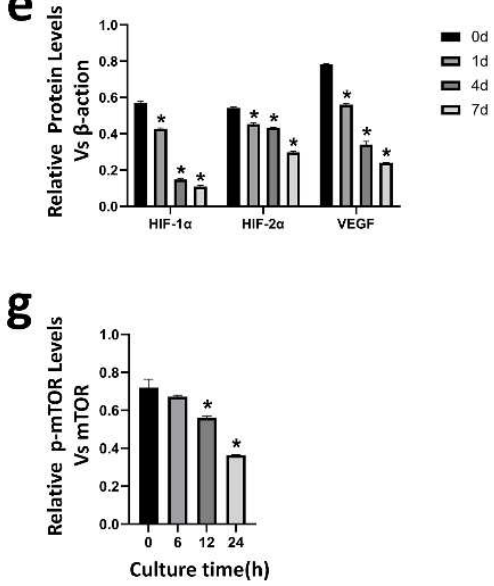

i

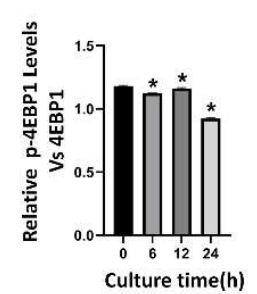

Fig. 4 Effect of sirolimus on the expression levels of mRNA and proteins related to angiogenic processes and the mTOR signalling pathway. (a-c) Relative mRNA expression levels of angiogenic factors in vascular endothelial cells treated with sirolimus for 1, 4 and 7 days. (d) Relative protein levels of angiogenic factors in vascular endothelial cells treated with sirolimus $(100 \mathrm{ng} / \mathrm{mL})$ for $0,1,4$ and 7 days. (e) Quantitative analysis of the relative protein levels of angiogenic factors vascular endothelial cells treated with sirolimus $(100 \mathrm{ng} / \mathrm{mL})$ for $0,1,4$ and 7 days. (f) Relative protein levels of mTOR signalling pathway-related factors vascular endothelial cells treated with sirolimus $(100 \mathrm{ng} / \mathrm{mL})$ for $0,6,12$ and 24 hours. (g-i) Quantitative analysis of the relative protein levels of mTOR signalling pathway-related factors vascular endothelial cells treated with sirolimus (100 ng/mL) for 0, 6, 12 and 24 hours. HIF-1 $\alpha$ : hypoxia inducible factor-1 alpha; HIF-2 $\alpha$ : hypoxia inducible factor-2 alpha; VEGF: vascular endothelial growth factor; mTOR: mammalian target of rapamycin; S6K1: ribosomal protein S6 kinase beta-1; 4EBP1: eukaryotic translation initiation factor 4E binding protein 1. $* p<0.05$ vs the control group. 
a

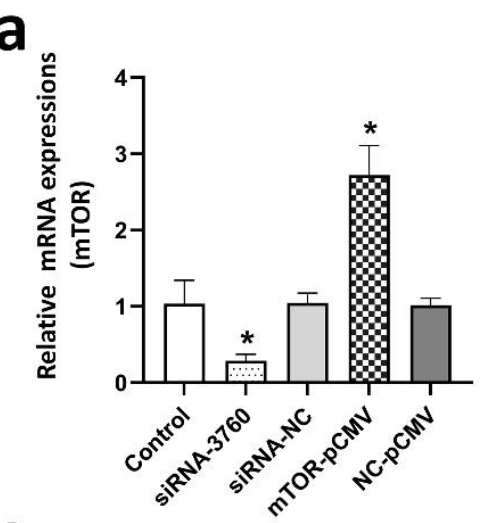

C

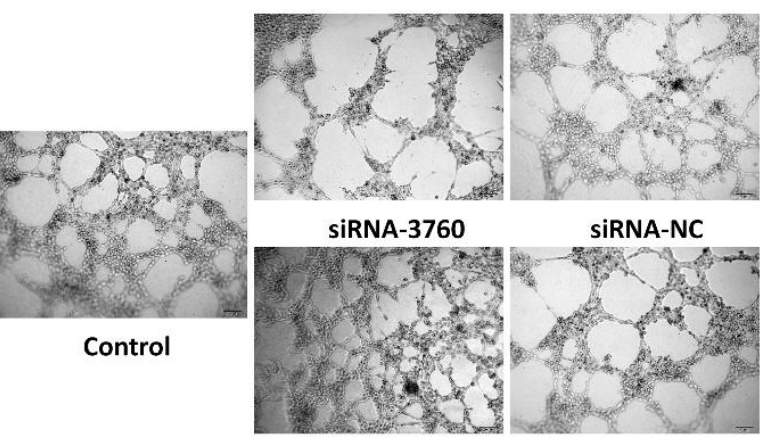

mTOR-pCMV

NC-pCMV b

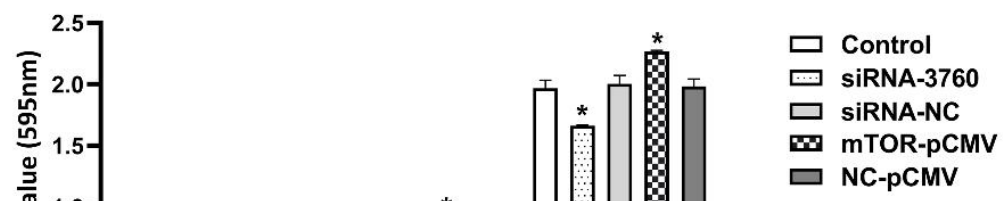

e

d

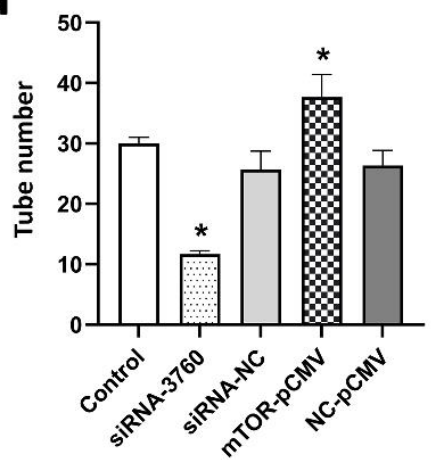

Control siRNA-3760 siRNA-NC mTOR-pCMV NC-pCMV

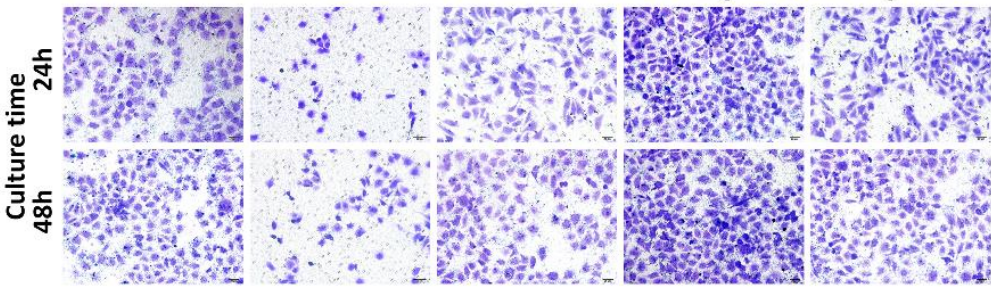

f

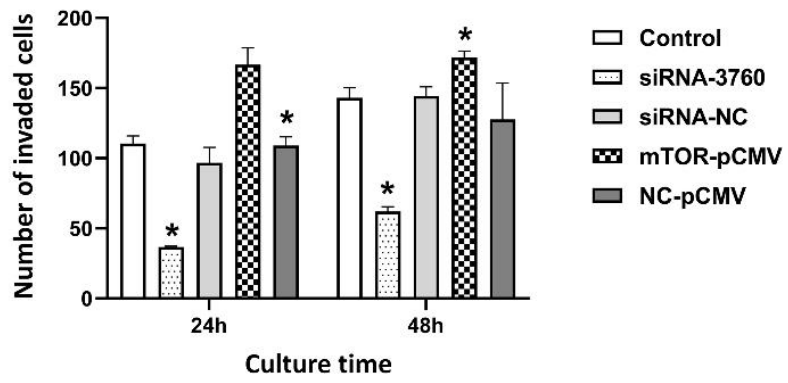

Fig. 5 Effect of mTOR on the biological behaviour of vascular endothelial cells in vitro. (a) PCR assays of mTOR after $48 \mathrm{~h}$ of mTOR expression regulation in vascular endothelial cells for confirmation. (b) CCK-8 proliferations assays of vascular endothelial cells after mTOR expression regulation. (c) Tube formation assays after $24 \mathrm{~h}$ of mTOR expression regulation in vascular endothelial cells. (d) Quantitative analysis of tube formation assays after $24 \mathrm{~h}$ of mTOR expression regulation in vascular endothelial cells. (e) Transwell assays after $24 \mathrm{~h}$ and $48 \mathrm{~h}$ of mTOR expression regulation in vascular endothelial cells. (f) Quantitative analysis of 
Transwell assays after $24 \mathrm{~h}$ and $48 \mathrm{~h}$ of mTOR expression regulation in vascular endothelial cells. Control: blank control group; siRNA-3760: mTOR interference RNA silencing group; siRNA NC: mTOR interference RNA negative control group; mTOR PCMV: mTOR plasmid overexpression group; NC PCMV: mTOR plasmid overexpression negative control group. ${ }^{*} p<0.05$ vs the control group. 
a

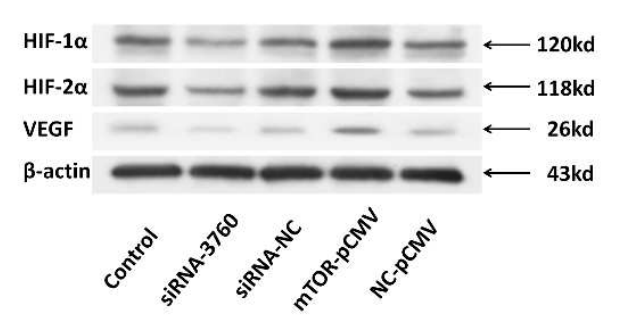

C

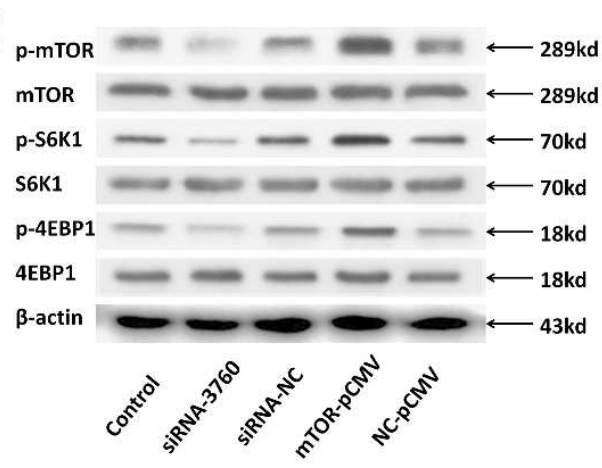

e

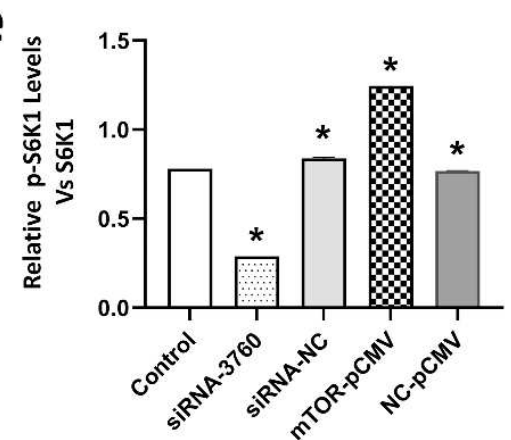

b

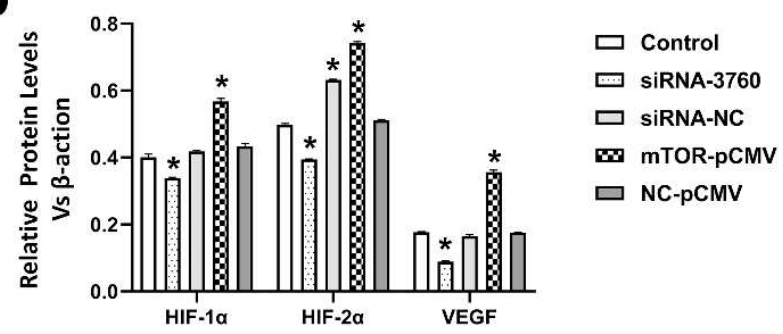

d

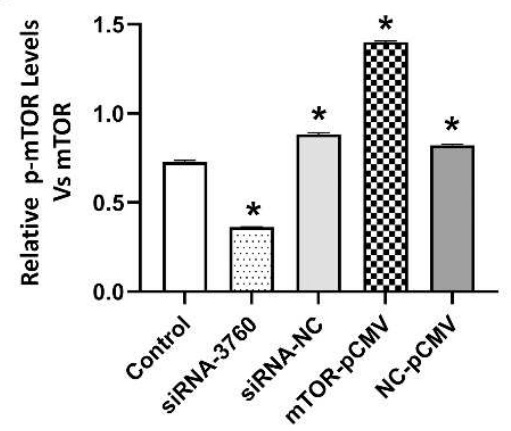

f

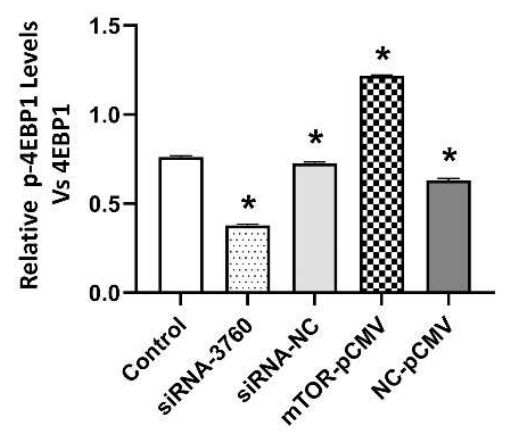

Fig. 6 Role of mTOR in the regulation of downstream protein expression. (a) Relative protein levels of angiogenic factors in vascular endothelial cells after 4 days of mTOR expression regulation. (b) Quantitative analysis of the relative protein levels of angiogenic factors in vascular endothelial cells after 4 days of mTOR expression regulation. (c) Relative protein levels of mTOR downstream factors in vascular endothelial cells after 48 hours of mTOR expression regulation. (d-f) Quantitative analysis of the relative protein levels of mTOR-related factors in vascular endothelial cells after 48 hours of mTOR expression regulation. HIF-1 $\alpha$ : hypoxia inducible factor-1 alpha; HIF-2 2 : hypoxia inducible factor-2 alpha; VEGF: vascular endothelial growth factor; mTOR: mammalian target of rapamycin; S6K1: ribosomal protein S6 kinase beta-1; 4EBP1: eukaryotic translation initiation factor $4 \mathrm{E}$ binding protein $1 .{ }^{*} p<0.05$ vs the control group. 


\section{Figures}

a

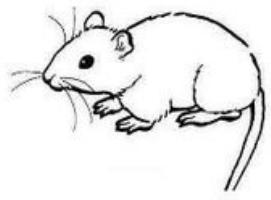

b

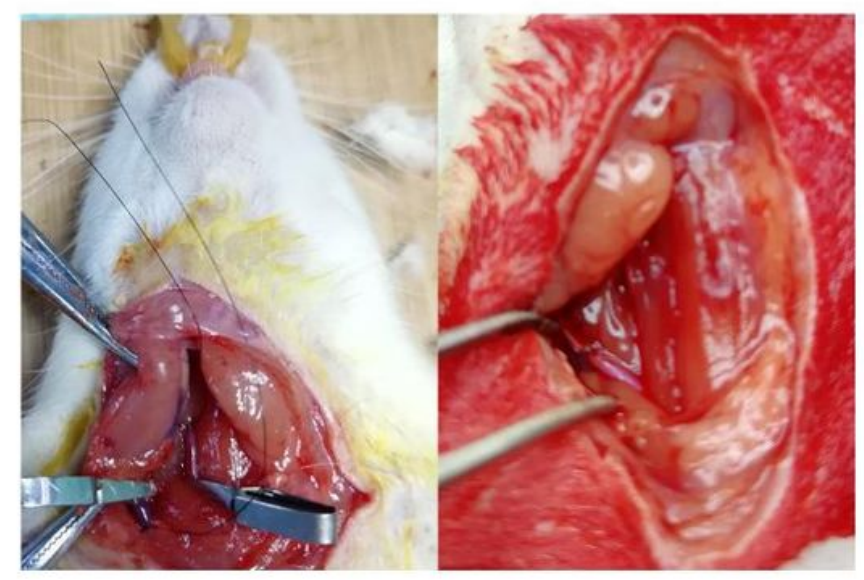

C

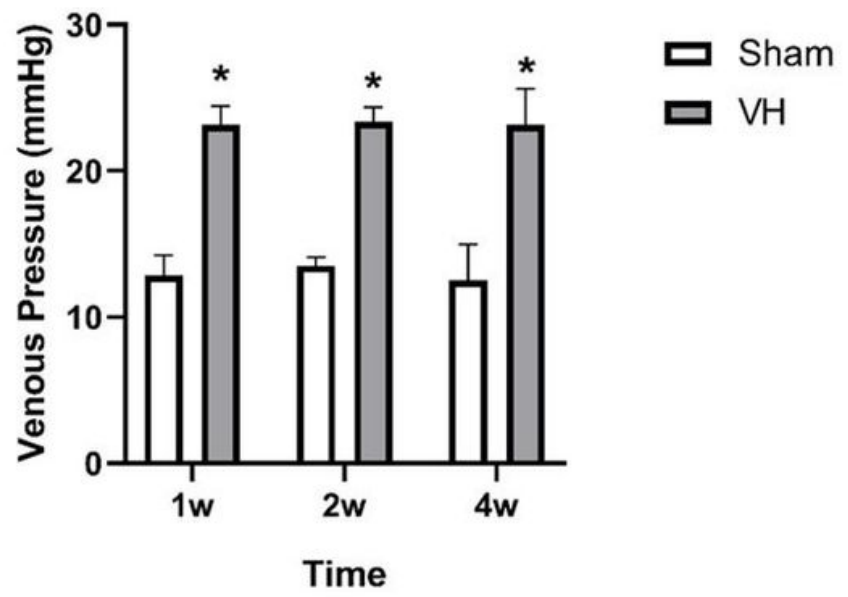

Figure 1

Establishment of the venous hypertension model. (a) Schematic diagram of the operation procedure. (b) Anastomosis of the common carotid artery and external jugular vein. (c) Venous pressure in the venous hypertension model 1, 2, and 4 weeks after the operation. CCA, common carotid artery. EJV, external jugular vein; Sham: sham group; $\mathrm{VH}$ : venous hypertension group. ${ }^{*} \mathrm{p}<0.05$ vs the sham group. 


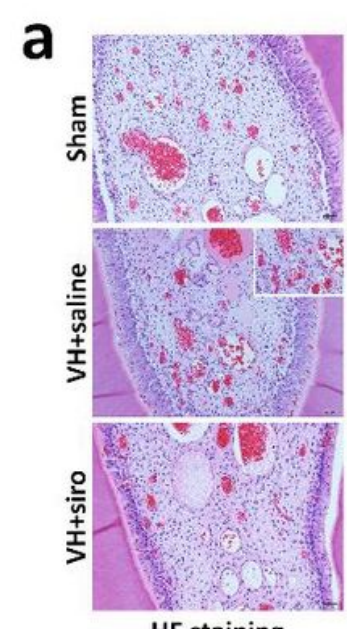

HE staining

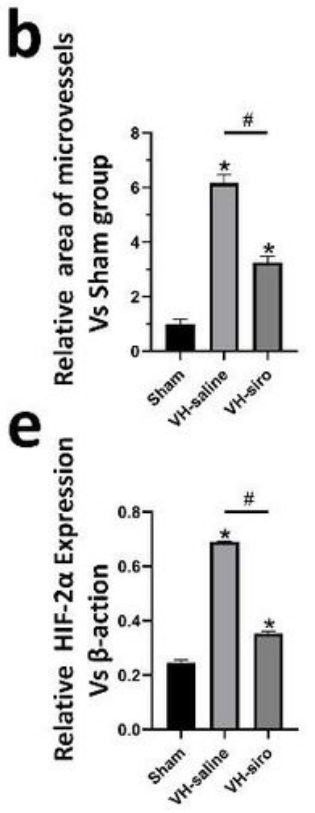

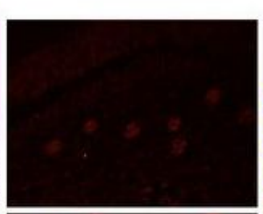
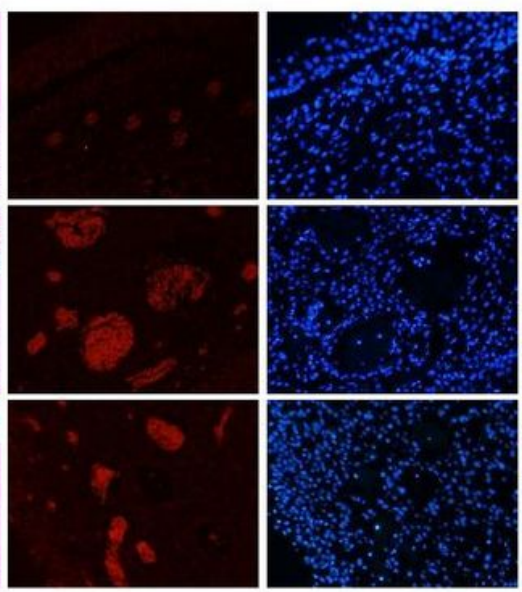

CD31

C
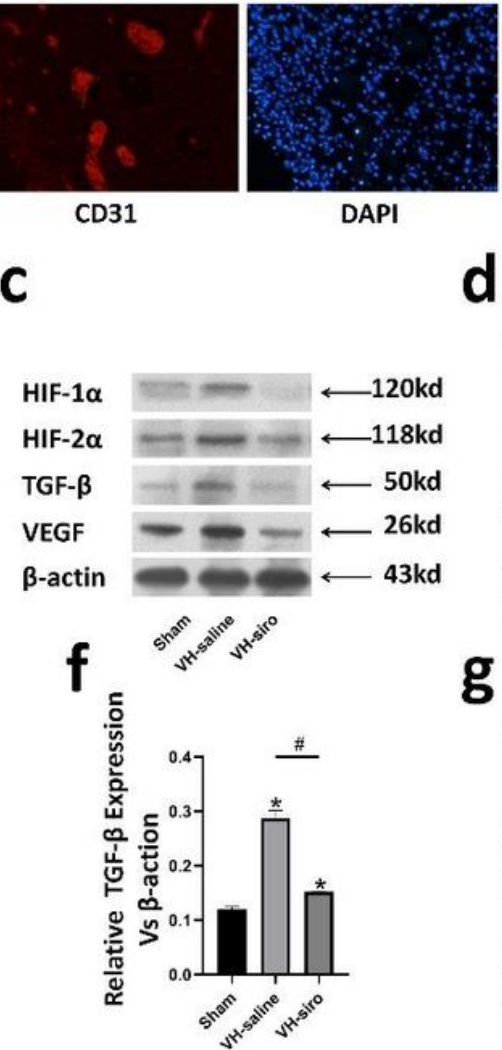

DAPI

g
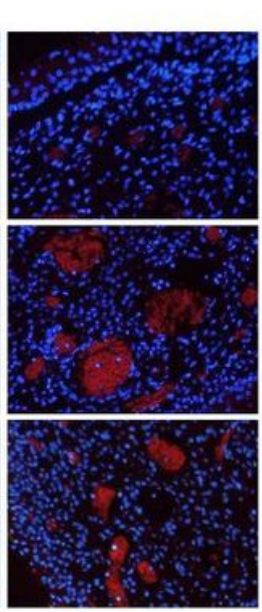

Merge

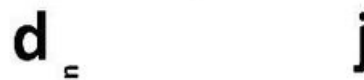

j

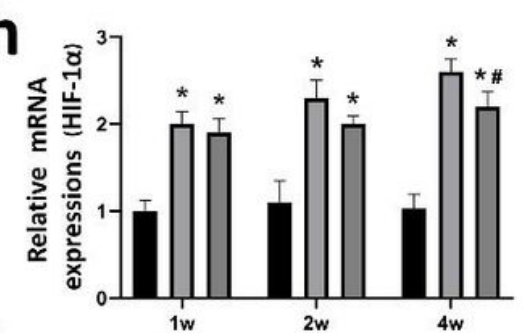

i
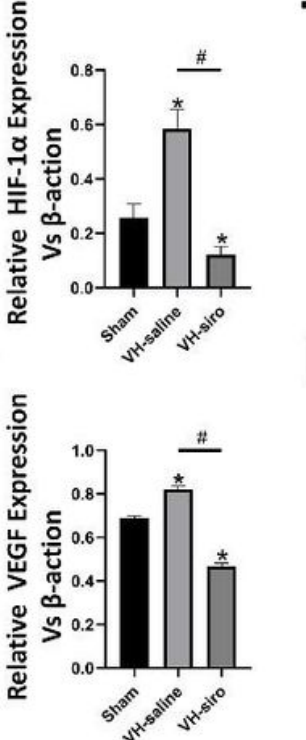
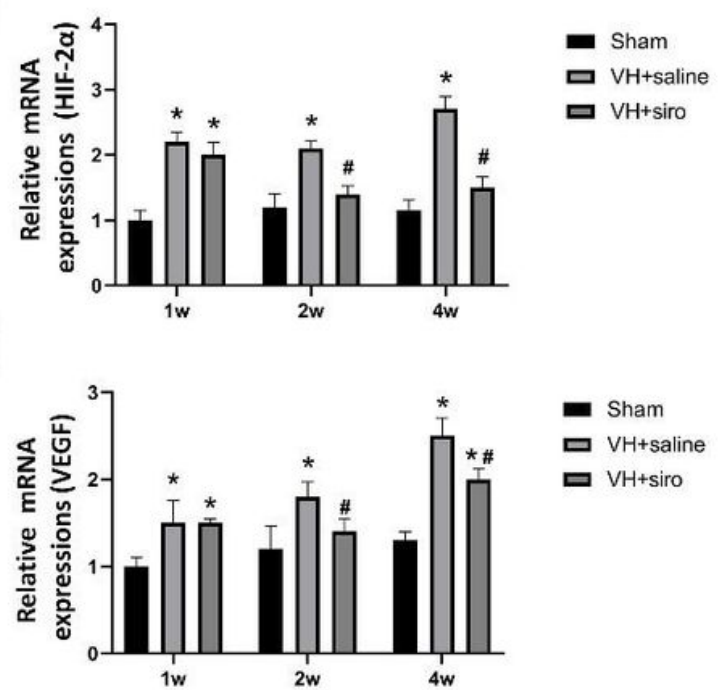

- Sham

口 $\mathrm{VH}+$ saline

口 $\mathrm{VH}+$ siro

k

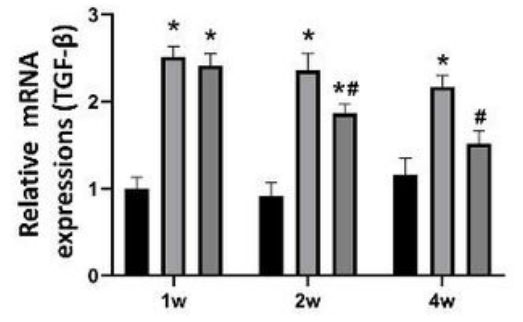

- Sham 口 $\mathrm{VH}+$ siro
- $\mathrm{VH}+$ saline

Figure 2

Sirolimus suppresses mandibular angiogenesis induced by VH in vivo. (a) Haematoxylin and eosin staining and immunofluorescence imaging of mandible in the venous hypertension model 4 weeks after the operation. (b) Relative area of microvessels in mandibular cancellous bone in the venous hypertension model 4 weeks after the operation. (c) Expression levels of angiogenic proteins in mandibular cancellous bone in the venous hypertension model 4 weeks after the operation. (d-g) Relative expression levels of angiogenic proteins in mandibular cancellous bone int the venous hypertension model 4 weeks after the operation. (h-k) Relative mRNA expression levels of angiogenic factors in mandibular cancellous bone in the venous hypertension model 1, 2 and 4 weeks after the operation. Sham: sham group; $\mathrm{VH}+$ saline: venous hypertension group that received a $20 \mathrm{~mL} / \mathrm{kg}$ BW solution ip; VH+siro: venous hypertension group that received a $20 \mathrm{~mL} / \mathrm{kg}$ BW solution ip plus sirolimus; HIF-1a: hypoxia inducible factor-1 alpha; HIF-2a: hypoxia inducible factor-2 alpha; TGF- $\beta$ : transforming growth factor-beta; VEGF: vascular endothelial growth factor. * $p<0.05$ vs the sham group; \# $p<0.05$ vs the $\mathrm{VH}+$ saline group. 
a

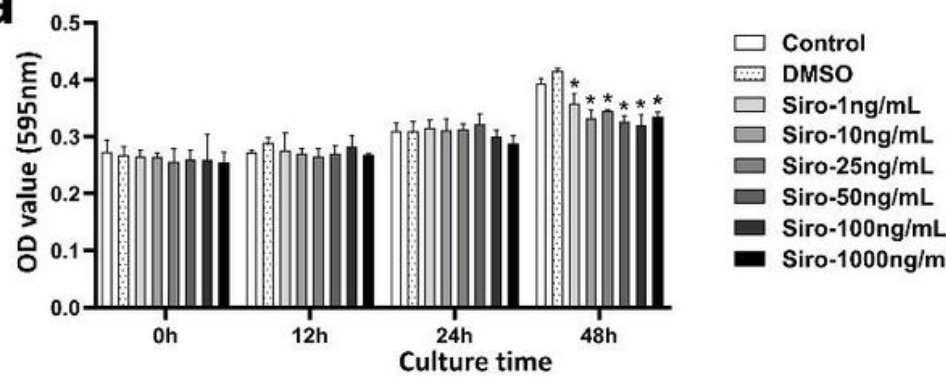

b
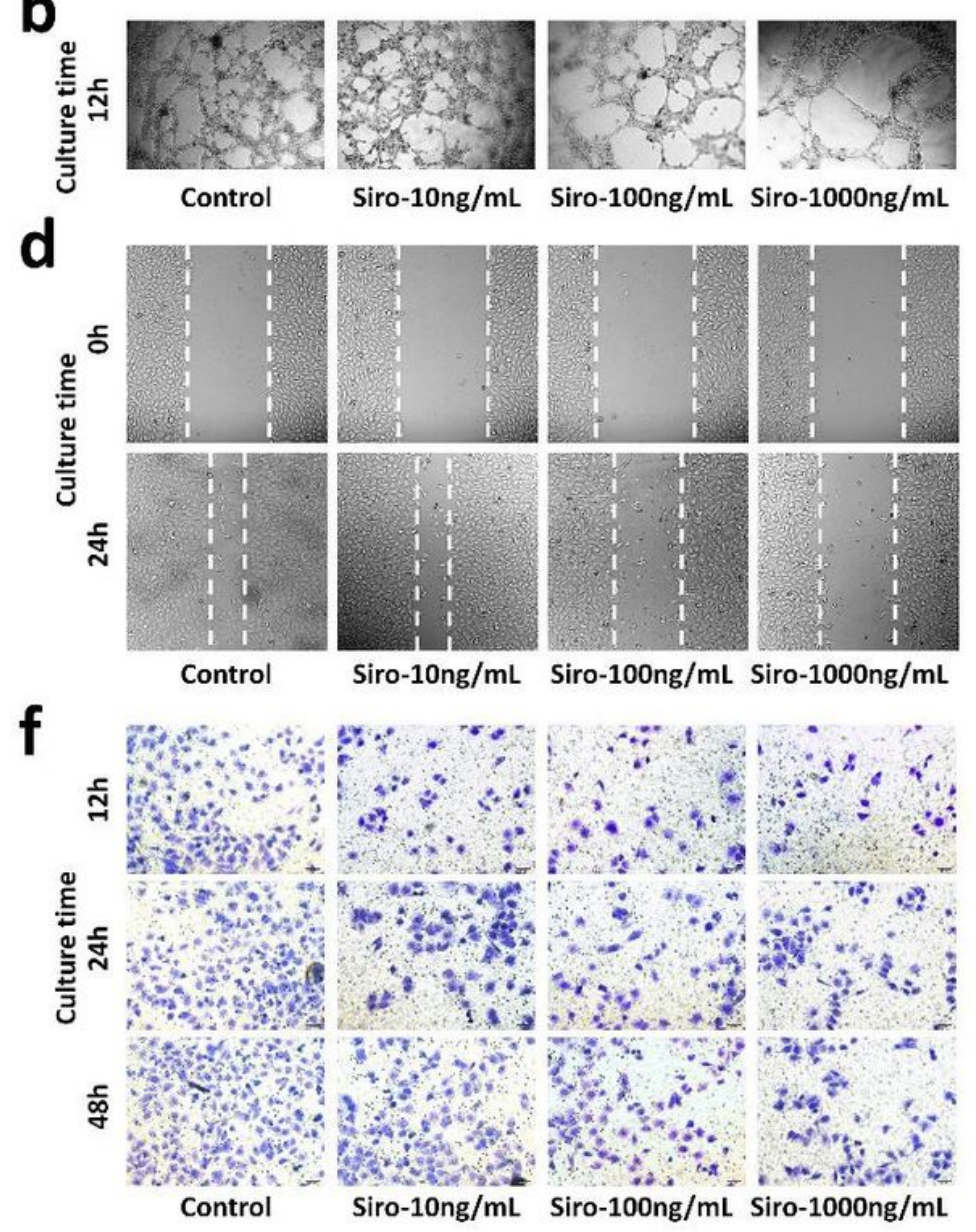

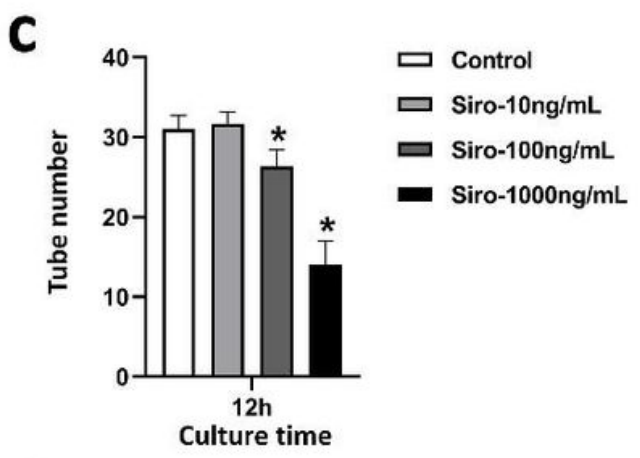

e

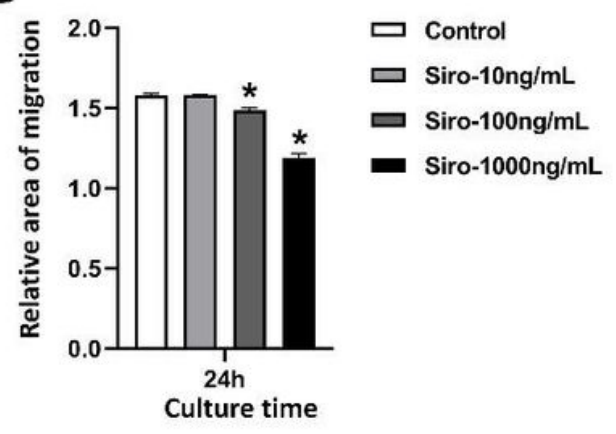

g

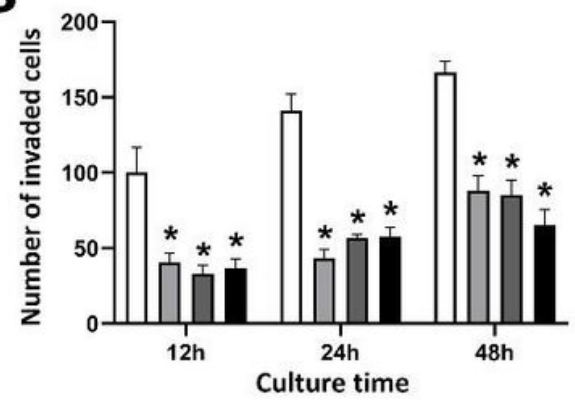

$\square$ Control

$\square$ Siro-10ng/mL

$\square$ Siro-100ng/mL

- Siro-1000ng $/ \mathrm{mL}$

\section{Figure 3}

Sirolimus regulates the biological behaviour of vascular endothelial cells in vitro. (a) CCK-8 proliferation assays of sirolimus-treated vascular endothelial cells. (b) Tube formation assays of vascular endothelial cells treated with sirolimus for $12 \mathrm{~h}$. (c) Quantitative analysis of the tube formation assays of vascular endothelial cells treated with sirolimus for $12 \mathrm{~h}$. (d) Scratch tests of vascular endothelial cells treated with sirolimus for $24 \mathrm{~h}$. (e) Quantitative analysis of the scratch tests of vascular endothelial cells treated with sirolimus for $24 \mathrm{~h}$. (f) Transwell invasion assays of vascular endothelial cells treated with sirolimus for 12, 24 and 48 h. (g) Quantitative analysis of Transwell invasion assays of vascular endothelial cells treated with sirolimus for 12, 24 and 48 h. Control: control group; DMSO: DMSO-treated group; Siro-n: group treated with different dosages of sirolimus * $p<0.05$ vs the control group. 


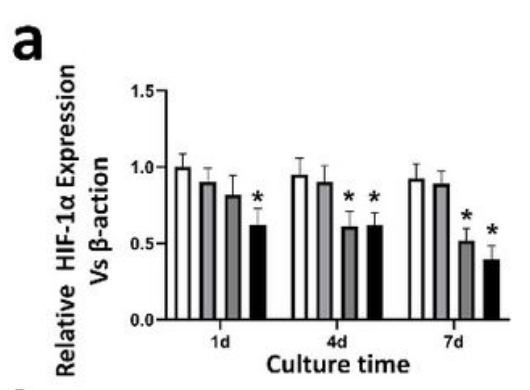

b

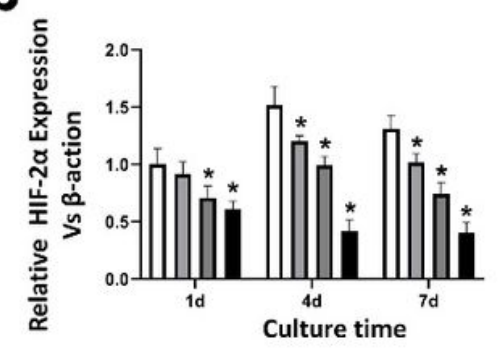

C

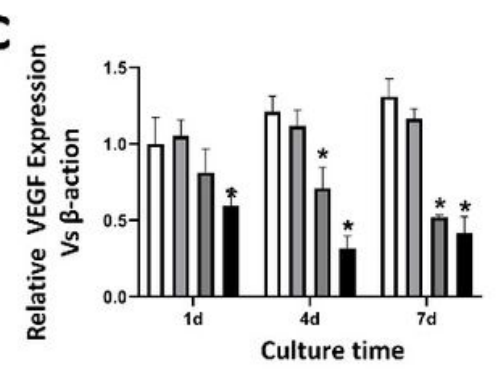

d
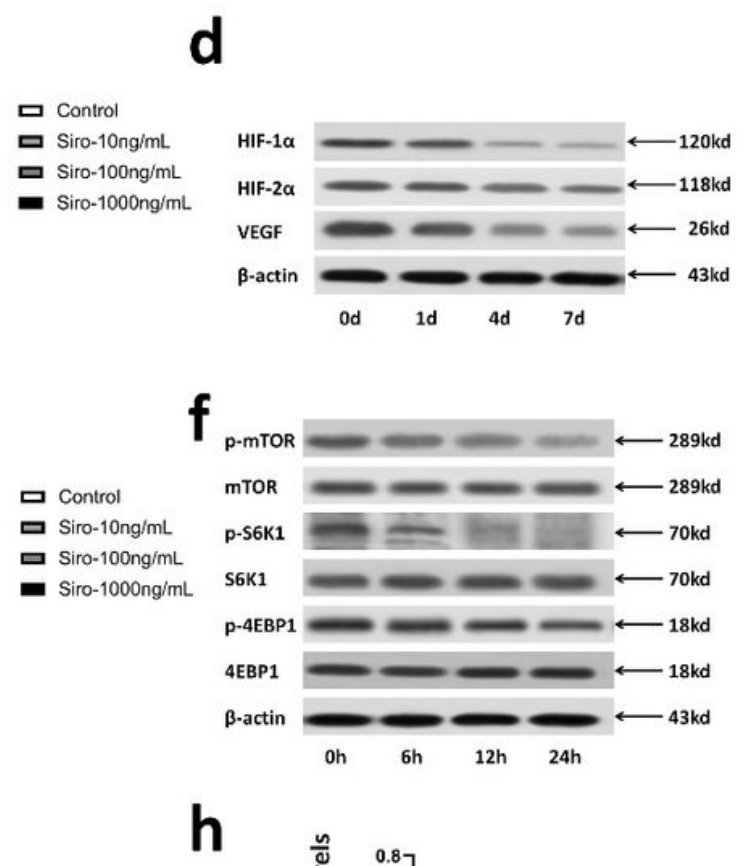

口 Control

口 Siro-10ng $/ \mathrm{mL}$

口 Siro-100ng/mL

- Siro-1000ng $/ \mathrm{mL}$
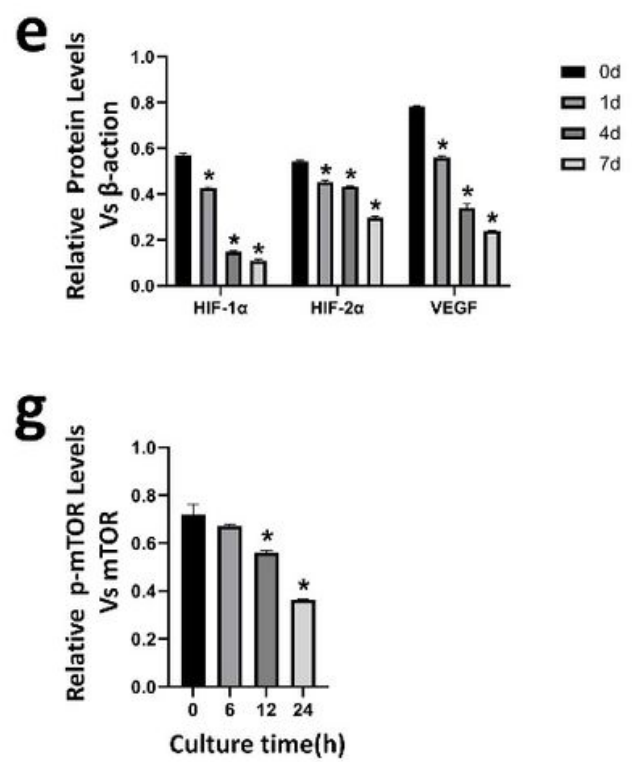

i

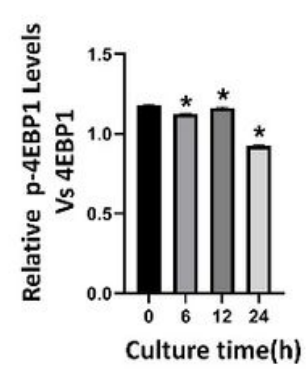

Figure 4

Effect of sirolimus on the expression levels of mRNA and proteins related to angiogenic processes and the mTOR signalling pathway. (a-c) Relative mRNA expression levels of angiogenic factors in vascular endothelial cells treated with sirolimus for 1, 4 and 7 days. (d) Relative protein levels of angiogenic factors in vascular endothelial cells treated with sirolimus $(100 \mathrm{ng} / \mathrm{mL})$ for $0,1,4$ and 7 days. (e) Quantitative analysis of the relative protein levels of angiogenic factors vascular endothelial cells treated with sirolimus ( $100 \mathrm{ng} / \mathrm{mL}$ ) for $0,1,4$ and 7 days. (f) Relative protein levels of $\mathrm{mTOR}$ signalling pathwayrelated factors vascular endothelial cells treated with sirolimus $(100 \mathrm{ng} / \mathrm{mL})$ for $0,6,12$ and 24 hours. (gi) Quantitative analysis of the relative protein levels of mTOR signalling pathway-related factors vascular endothelial cells treated with sirolimus $(100 \mathrm{ng} / \mathrm{mL})$ for $0,6,12$ and 24 hours. HIF-1a: hypoxia inducible factor-1 alpha; HIF-2a: hypoxia inducible factor-2 alpha; VEGF: vascular endothelial growth factor; mTOR: mammalian target of rapamycin; S6K1: ribosomal protein S6 kinase beta-1; 4EBP1: eukaryotic translation initiation factor $4 \mathrm{E}$ binding protein $1 .{ }^{*} \mathrm{p}<0.05$ vs the control group. 


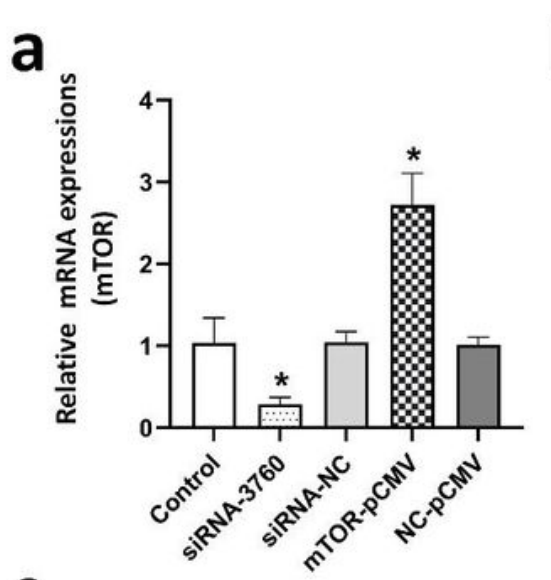

C

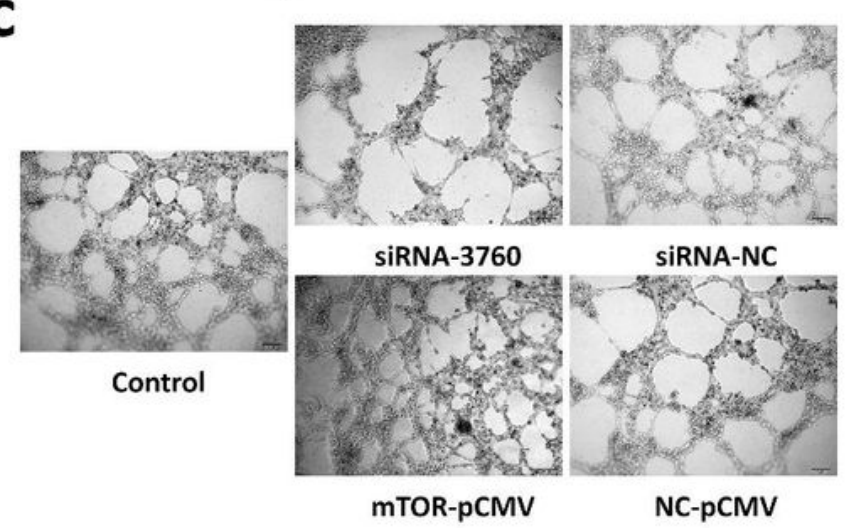

b

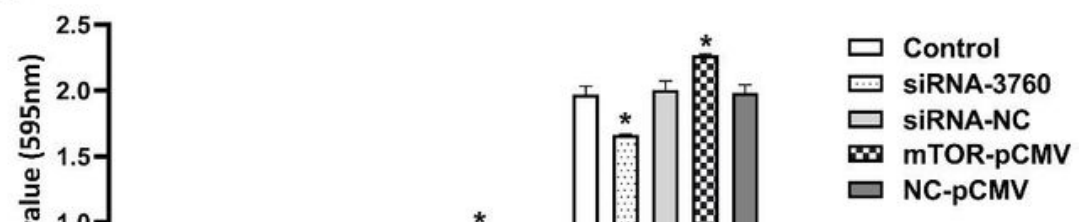

e

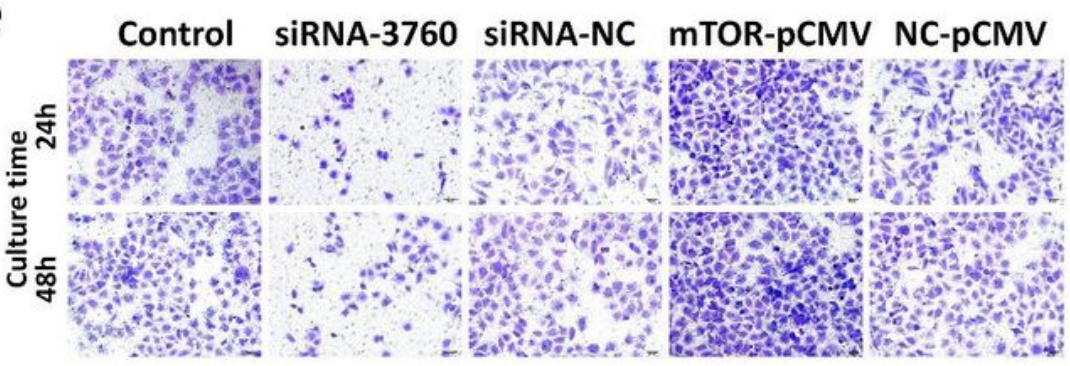

f

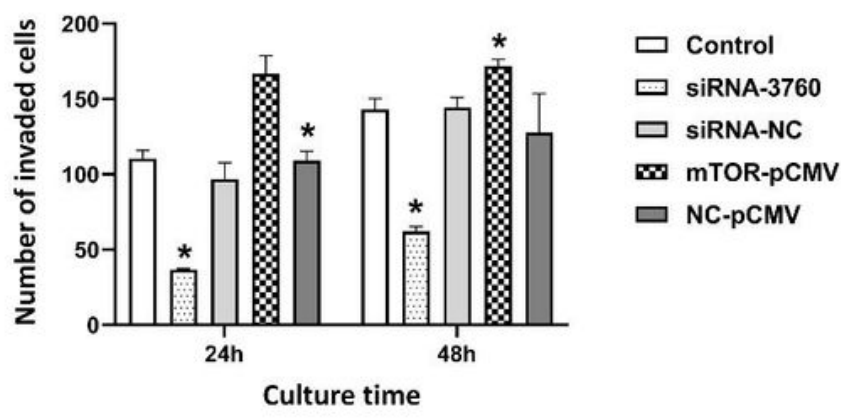

Figure 5

Effect of mTOR on the biological behaviour of vascular endothelial cells in vitro. (a) PCR assays of mTOR after $48 \mathrm{~h}$ of mTOR expression regulation in vascular endothelial cells for confirmation. (b) CCK-8 proliferations assays of vascular endothelial cells after mTOR expression regulation. (c) Tube formation assays after $24 \mathrm{~h}$ of mTOR expression regulation in vascular endothelial cells. (d) Quantitative analysis of tube formation assays after $24 \mathrm{~h}$ of mTOR expression regulation in vascular endothelial cells. (e) 
Transwell assays after $24 \mathrm{~h}$ and $48 \mathrm{~h}$ of mTOR expression regulation in vascular endothelial cells. (f) Quantitative analysis of Transwell assays after $24 \mathrm{~h}$ and $48 \mathrm{~h}$ of mTOR expression regulation in vascular endothelial cells. Control: blank control group; siRNA-3760: mTOR interference RNA silencing group; siRNA NC: mTOR interference RNA negative control group; mTOR PCMV: mTOR plasmid overexpression group; NC PCMV: mTOR plasmid overexpression negative control group. * $p<0.05$ vs the control group.

a
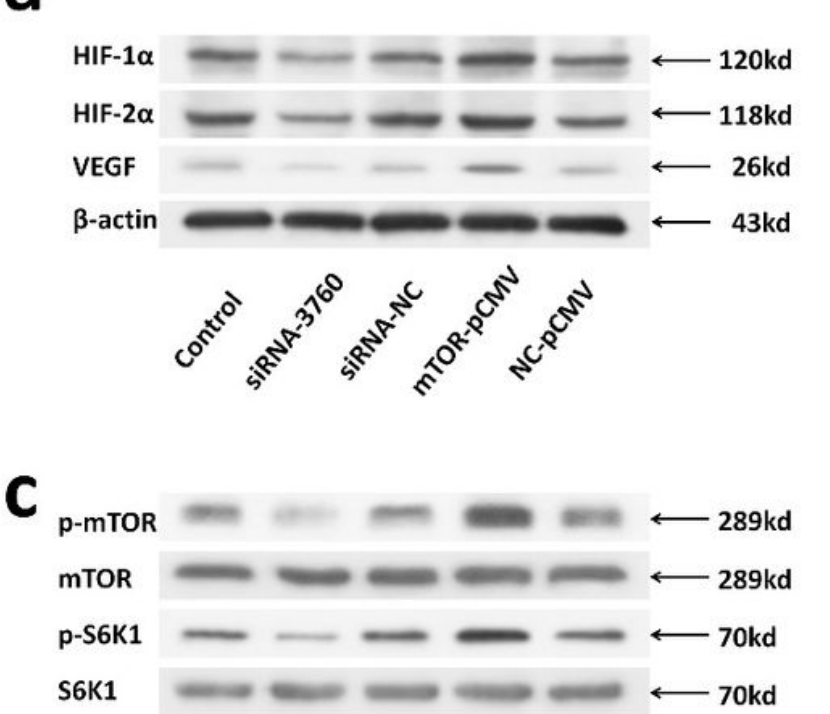

p-4EBP1 $--\leftarrow$ 18kd

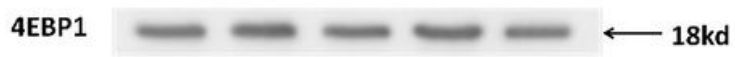

$\beta$-actin $\longrightarrow \longrightarrow \longrightarrow$

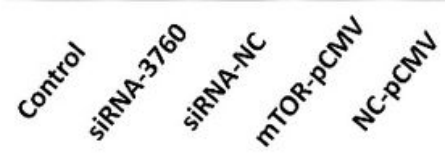

e

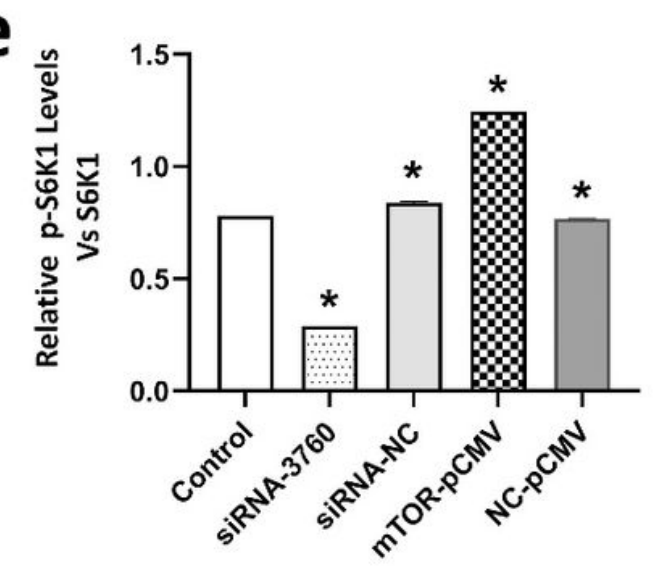

b

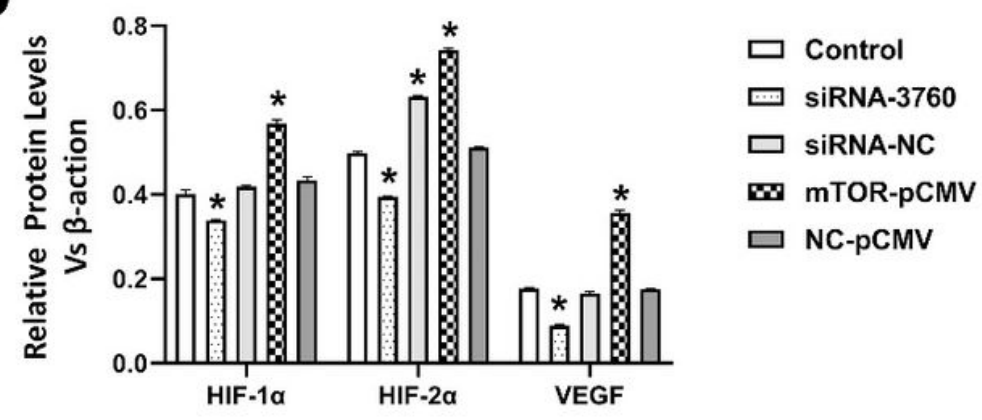

d

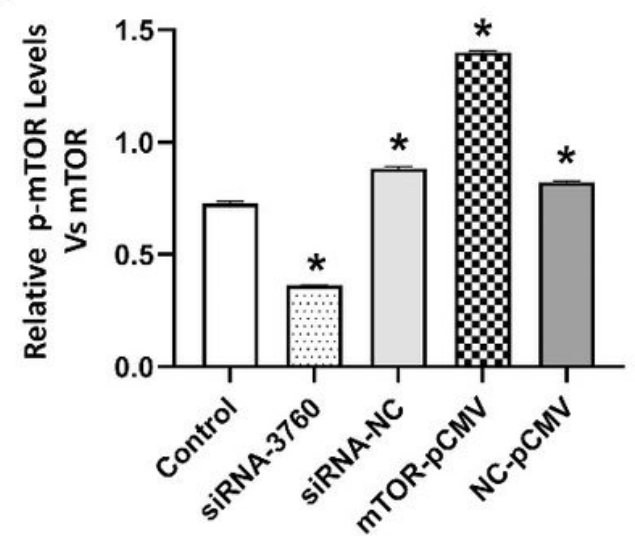

f

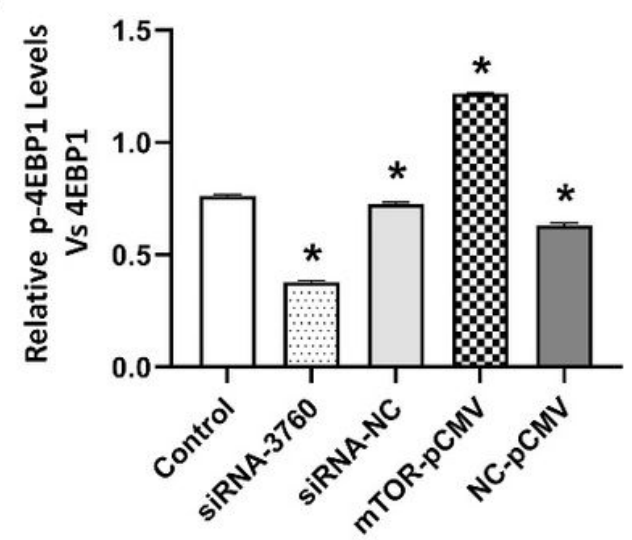

Figure 6

Role of mTOR in the regulation of downstream protein expression. (a) Relative protein levels of angiogenic factors in vascular endothelial cells after 4 days of mTOR expression regulation. (b) Quantitative analysis of the relative protein levels of angiogenic factors in vascular endothelial cells after 4 days of mTOR expression regulation. (c) Relative protein levels of mTOR downstream factors in 
vascular endothelial cells after 48 hours of mTOR expression regulation. (d-f) Quantitative analysis of the relative protein levels of mTOR-related factors in vascular endothelial cells after 48 hours of mTOR expression regulation. HIF-1a: hypoxia inducible factor-1 alpha; HIF-2a: hypoxia inducible factor-2 alpha; VEGF: vascular endothelial growth factor; mTOR: mammalian target of rapamycin; S6K1: ribosomal protein S6 kinase beta-1; 4EBP1: eukaryotic translation initiation factor $4 \mathrm{E}$ binding protein $1 .{ }^{*} \mathrm{p}<0.05 \mathrm{vs}$ the control group.

\section{Supplementary Files}

This is a list of supplementary files associated with this preprint. Click to download.

- SupplementaryFile1.docx

- SupplementaryFile2.docx

- Supplementaryfile3.txt 